\title{
Genetic analysis of the slow melting flesh character in peach
}

Octávio Serra ${ }^{1}$, Jordi Giné-Bordonaba ${ }^{2}$, Iban Eduardo ${ }^{1}$, Joan Bonany ${ }^{3}$, Gemma Echeverria ${ }^{2}$, Christian Larrigaudière $^{2}$ and Pere Arús ${ }^{1 \S}$

${ }^{1}$ IRTA. Centre de Recerca en Agrigenòmica CSIC-IRTA-UAB-UB, Campus UAB, Cerdanyola del Vallès (Bellaterra), 08193 Barcelona, Spain;

${ }^{2}$ IRTA. Fruitcentre, 25003 Lleida, Spain;

${ }^{3}$ IRTA. Mas Badia, 17134 La Tallada, Spain

${ }^{\S}$ Corresponding author: e-mail: pere.arus@irta.cat; phone: +34607072923; fax: +34935636601 


\begin{abstract}
The slow melting flesh (SMF) trait in peach [Prunus persica (L.) Batsch] defines a slower process of postharvest fruit softening than the prevalent melting flesh (MF) types. This gives a longer shelf-life and a delayed harvest time resulting in better fruit quality. Unlike other known fruit texture traits, SMF is difficult to measure and has a complex inheritance. We examined this character over two years in the offspring of two crosses, both with 'Big Top', a SMF nectarine, as female parent, and a melting flesh (MF) nectarine as male parent ('Armking' and 'Nectaross'). Following harvest, a texturometer was used to provide a textural profile analysis, and fruit firmness evolution was measured with a penetrometer over a period of 5 days' storage at $20^{\circ} \mathrm{C}$. Linkage maps were constructed with a high density SNP chip, and a phenotype-genotype analysis allowed the detection of three independent genomic regions where most QTLs (quantitative trait loci) were located. Two of these, on linkage groups 4 and 5, explained the variability for two characters - maturity date and firmness loss - that is, the QTL on linkage group 4 found in the MF parents and that on linkage group 5 in 'Big Top'. A third region on linkage group 6, identified a QTL for maturity date only in 'Armking', having no apparent association to the softening process. The relationship between maturity date and fruit firmness loss and a hypothesis on the inheritance of the SMF character are discussed.
\end{abstract}

Keywords: Prunus persica, postharvest behavior, marker-assisted selection, maturity date, fruit flesh texture

\title{
Acknowledgments
}

We acknowledge financial support from the Spanish Ministry of Economy and Competitiveness, through the project AGL2015-68329-R, from "Severo Ochoa Programme for Centres of Excellence in R\&D" 2016-2019 (SEV-2015-0533)”, from the CERCA Programme-Generalitat de Catalunya and from the EU seventh Framework program by the FruitBreedomics project (FP7-KBBE-2010-265582): an Integrated Approach for Increasing Breeding Efficiency in Fruit Tree Crop. The views expressed in this work are the sole responsibility of the authors and do not necessary reflect the views of the European Commission. We thank Arsène and Laurance Maillard from Agro Selection Fruits for their advice in the selection of the parents of the progenies used in this paper. 


\section{Introduction}

Postharvest behavior is a critical aspect of quality in the climacteric peach fruit. Depending on the postharvest conditions peaches can be kept at most for three to four weeks after harvest (Ramina et al. 2008). The key aspect determining peach fruit shelf-life is softening, with the melting flesh (MF) types, which dominate the peach fresh market, having the fastest softening rate and consequently the most reduced postharvest life. Increasing shelf-life has been one of the main objectives of breeding programs although the progress has been, to date, quite limited.

Three peach variants capable of retaining the flesh consistency after harvest have been characterized both at the genetic and physiological level. One is non-melting flesh (NMF), characteristic of canning peaches, where fruit texture is firm at maturity, softening slowly after ripening without melting (Bassi and Monet 2008). This character is determined by a major gene $(\mathrm{M} / \mathrm{m})$ located in the central region of linkage group 4 (G4) of the peach map (Peace et al. 2005), with the recessive allele ( $m$ ) determining the non-melting character. The causal gene of $M$ has been associated with the activity of an endopolygalacturonase gene in peach (Lester et al. 1996). In fact, $M$ co-locates with the position of a genomic region with various endopolygalacturonase genes, two of which, PpEndoPGM and PpendoPGF, corresponding to sequences Prupe.4G262200 in v2.0.a1 of the peach genome (ppa006857m in v1.0) and Prupe.4G261900 (ppa006839m in v1.0), respectively, are responsible for the MF vs. NMF and the clingstone vs. freestone characters ( $\mathrm{Gu}$ et al. 2016). Another trait related with fruit firmness is the stony-hard (SH) flesh type, determined by a single gene $H d / h d$, where fruit of stony-hard individuals bearing the hdhd genotype are characterized by the absence of ethylene production and with high firmness values during postharvest storage (Haji et al. 2001, 2005; Begheldo et al. 2008; Giné-Bordonaba et al. 2016). Nonetheless, exogenous application of ethylene to SH fruit has been shown to promote postharvest softening (Haji et al. 2001; Hayama et al. 2006). This character has been studied in detail by Pan et al. (2015), who identified a YUCCA flavin mono-oxygenase gene (PpYUC11, ppa008176m in v1.0, and Prupe.6G157400 and Prupe.6G157500 in v2.0.a1 of the peach genome) in the central part of chromosome 6 , involved in the auxin biosynthesis pathway, as a strong candidate for the $H d$ gene. A high concentration of IAA (indol-3 acetic acid) is required for the normal climacteric ripening process: the $h d$ allele of PpYUC11 results in a dramatic decrease of IAA accumulation in stony-hard fruit, thereby impairing ethylene production.

The third trait is for slow ripening (SR) fruit where peaches do not mature and soften at all, even after treatment with ethylene, and remain attached to the tree after leaf fall. This character is determined by a single gene, Sr/sr (Ramming 1991), located on chromosome 4 (Eduardo et al. 2015; Núñez-Lillo et al. 2015), but at a different position from the $M / m$ gene. A candidate gene for this character is a NAC transcription factor (ppa008301m in v1.0; Prupe.4G186800 in v2.0.a1) responsible for controlling the ethylene pathway and possibly involved in peach maturity date (Pirona et al. 2013; Eduardo et al. 2015). In contrast to all the above-mentioned, slow melting flesh (SMF) peaches also produce fruit that are hard at physiological maturity, similar to MF peaches, but melt at slower rate than MF types during postharvest (Bassi and Monet 2008). These features are appreciated by growers and retailers as fruit can 
be harvested at a more advanced stage of maturity and shelf-life is extended. In addition, advanced maturity at harvest may lead to fruit with improved organoleptic quality by increasing the sugar content (Iglesias and Echeverría, 2009). From a physiological point of view, no strong relationships between the rate of firmness loss and the capacity of the fruit to produce ethylene have been found when comparing SMF and MF varieties (Ghiani et al. 2011; Giné-Bordonaba et al. 2016). Several peach and nectarine cultivars from Californian breeders have this SMF character, such as the 'Rich Lady' and 'Diamond Princess' peaches, and the red-skinned, yellow-fleshed nectarine 'Big Top', which has become a reference for Spanish nectarine production over the last decade (Iglesias 2012).

Unlike the other three characters (NMF, SH and SR), that have a simple Mendelian inheritance, SMF is poorly characterized at the genetic level, in part due to the difficulty of measuring this character (Bassi and Monet, 2008). A first approach has been recently provided by Zeballos et al. (2016), who measured fruit firmness in a 'Big Top' $\times$ 'Venus' population and found a QTL on G5 of the 'Big Top' map which explained approximately $20 \%$ of the total variation for this character. In this paper we analyze two segregating progenies with 'Big Top' as one of the parents, and analyze their fruits for several parameters related with flesh texture. By doing so, we attempt to provide additional evidence to help in understanding the genetic basis of this important character and to facilitate the incorporation of SMF in new varieties through breeding programs.

\section{Materials and Methods}

$\underline{\text { Plant populations }}$

In this work we used two yellow-fleshed nectarine F1 populations. The first population ( $\mathrm{N}=75)$ was from the cross between 'Big Top' and 'Armking' (Bt×Ak), and the second $(\mathrm{N}=48)$ from crossing 'Big Top' and 'Nectaross' $(\mathrm{Bt} \times \mathrm{Nr})$. 'Armking' and 'Nectaross', both regular melting $(\mathrm{MF})$ varieties, were used as pollen donors, whereas 'Big Top' is a SMF variety that was the pistillate parent. Both populations and parental lines were grafted on 'Garnem' rootstock and grown using standard cultural practices at IRTA's experimental station in Gimenells, Lleida (Spain).

\section{Phenotyping and data analysis}

Fruits were harvested at optimum commercial maturity based on grower's recommendations and their firmness values reached 50.0 \pm 5.0 Newtons. Additionally, the visual inspection of all fruits for each tree to confirm the appropriate ripe stage of each individual and the maturity date $(\mathrm{MD}=$ number of Julian days till harvest day) was further recorded. The apparent maturity of each individual fruit, based on the index of absorbance difference $\left(\mathrm{I}_{\mathrm{AD}}=\mathrm{A}_{670}-\mathrm{A}_{720}\right.$; Ziosi et al. 2008; DA-Meter, TR Turoni, Forli, Italy), was assessed in the laboratory, and fruit with homogenous medium apparent maturity (based on a normal distribution) were selected $(n=50)$ for further analysis and stored at $20^{\circ} \mathrm{C}$ (Giné-Bordonaba et al. 2016). Samples were taken after $0,1,2,3$ and 5 days storage to measure fruit firmness by means of a hand-held penetrometer, equipped with an $8 \mathrm{~mm}$ plunger (Effegi, Milan, Italy), after removing the peel of the fruit on 
two opposite sides. The percentage of firmness loss was calculated at day three (FL3d) and five (FL5d) by dividing the corresponding firmness by the initial fruit firmness (F0) and multiplying by 100 . Additionally, we studied the textural properties of the fruit flesh on the day of harvest, performing a texture profile analysis (TPA) on an additional ten fruits per individual. TPA was with a TA-XTplus Texture Analyzer (Stable Micro Systems Ltd, Godalming, Surrey, UK) equipped with a P/75 flat probe, using the following test conditions: pre-test speed, $2 \mathrm{~mm} / \mathrm{s}$; test and post-test speed, $5 \mathrm{~mm} / \mathrm{s}$; and $50 \%$ deformation with an activation force of $0.05 \mathrm{~N}$. The textural parameters obtained were Hardness, Springiness, Gumminess, Resilience, Chewiness and Cohesiveness (see Bourne 2002, for a detailed description of TPA parameters and their relationship with sensory ratings).

All data were analyzed with R v3.2.1 (R Core Team 2015). We tested for data normality using a ShapiroWilk test, with data being considered not normal if $\mathrm{p}$-value $<0.05$. Traits in different years were correlated with the Spearman's rank correlation coefficient.

Genotyping and linkage map construction

Genomic DNA was extracted from young leaves using the CTAB method (Doyle and Doyle, 1990), followed by a purification step using columns from the DNeasy plant extraction kit (Qiagen, Hilden, Germany). Linkage maps were built using a set of 24 microsatellite (or simple-sequence repeats, SSR) markers (Table 1S) and the segregating SNP markers obtained with the 9K Illumina SNP chip developed by the Peach SNP International Consortium (Verde et al. 2012). For SNPs, genotypes were scored with GenomeStudio data analysis software (Illumina Inc.) following the same criteria as in Donoso et al. (2015).

All SNPs heterozygous in one or both parents were included for mapping except those that lacked one of the expected genotypic classes (two for 1:1 and three for 1:2:1 ratios). A map was initially constructed for the parents of both progenies. Depending on the genotype of each parent, markers segregated 1:1 when only one parent was heterozygous, and 1:2:1 when both parents were heterozygous for the same alleles. Markers with 1:2:1 ratios were converted into 1:1 by discarding the heterozygous genotypes and using only the two homozygous classes. The phase for the latter markers was determined by comparing them with other 1:1 markers in the same chromosome region. SSRs segregating 1:1:1:1 (both parents heterozygous and segregations involved three or four alleles) were converted into two 1:1 segregations, one for each parent, based on their genotype. We grouped all the markers that co-segregated and selected only one as a representative of the entire region or 'bin'. The mapping data file used for map construction consisted only of one marker per bin, so reducing the complexity of map construction. Maps were built with MAPMAKER/EXP 3.0 software (Lander et al. 1987) using the Kosambi mapping function. Markers were grouped with a minimum LOD score of 4.0 and a maximum gap of $37.5 \mathrm{cM}$. Based on these criteria, we built the genetic linkage maps for the three parental lines: 'Big Top' (Bt), 'Armking' (Ak) and 'Nectaross' (Nr). In the case of 'Big Top', we first built two different maps, one for each population. Then we constructed a consensus map of 'Big Top' using data from the 123 individuals of the two populations at once, since the markers that segregate for this line are expected to be the same in each population dataset, resulting in a more accurate genetic map than either of the individual 'Big Top' maps. 
QTL analysis

QTLs were detected using MapQTL 6.0 ® (Van Ooijen 2009) using interval mapping (IM) and the Kruskal-Wallis test. The data were initially analyzed using the maps of each parent ('Armking', 'Nectaross' and twice 'Big Top', one for Bt $\times \mathrm{Ak}$ and the other for $\mathrm{Bt} \times \mathrm{Nr}$ ) as a $\mathrm{BC} 1$ population taking only 1:1 segregations, including those derived from 1:2:1 and 1:1:1:1 ratios, as described above. This made it possible to identify in which parent the QTL was heterozygous or if it was heterozygous in both parents. An additional analysis taking data from all markers (1:1 and full 1:2:1/1:1:1:1 segregations) of Bt×Ak and Bt $\times \mathrm{Nr}$ with the CP mode of MapQTL allowed a better estimation of QTLs that were heterozygous in both parents. The significance threshold for a QTL was LOD $\geq 3.0$ although, exceptionally, QTLs with $3.0 \geq \mathrm{LOD} \geq 2.0$ one year were also considered if there was a QTL with a $\mathrm{LOD} \geq 3.0$ in the same region in the other year. Additionally, all QTLs accepted required a significant Kruskal-Wallis test with $\mathrm{p} \leq 0.01$ at the position of the marker closest to the maximum LOD. A QTL was defined as consistent when it was detected at the same region of the same population in both seasons.

The regions containing the QTLs were defined by the genome fragment between the markers having the maximum LOD minus one and a broader fragment with LOD minus two. We studied in more detail the QTLs for maturity date on G5 and G6 and for them estimated the joint interval for the data from 2013 and 2014 by the most extreme markers of the regions (LOD-1) identified both years. The protein sequence of gene Prupe.4G186800, the candidate for the maturity date (MD) gene located on G4, was used to look for homologues of this NAC transcription factor gene in the peach genome and in these two QTL regions. Blast was performed through GDR webpage (https://www.rosaceae.org/tools/ncbi_blast) using blastp program (Altschul et al. 1997), looking for matches in the peach genome sequence v2.0.a1 with the database of all transcript peptides.

\section{Results}

\section{Linkage maps}

The 9K Illumina SNP chip and the 24 SSRs used provided information on a total of 2,201 segregating markers in Bt×Ak and 2,362 in Bt $\times$ Nr. Most of them coalesced in the eight chromosomes of peach: 2,198 (99\%) in Bt $\times \mathrm{Ak}$ and 2,318 (98\%) in $\mathrm{Bt} \times \mathrm{Nr}$ and the rest were unmapped. For the mapped markers, the majority were heterozygous in only one of the parents and segregated 1:1; 1,707 (78\%) in BtxAk and $1,673(72 \%)$ in Bt $\times N r$. The remaining 22-28\% of the markers, segregating 1:2:1, corresponded to chromosomal regions heterozygous in both parents and mapped alone occasionally, tending to cluster in specific regions of the genome, mixed with other markers segregating 1:1 that were generally much less abundant in these regions. The patterns of these regions were specific for each particular cross and represented $8 \%$ of the total physical distance of the Bt $\times \mathrm{Ak}$ and $16 \%$ of the Bt $\times \mathrm{Nr}$ maps.

Considering the data used for the construction of the map for each parent (Table 1), the map of 'Big Top' (using the ensemble of data of the 123 individuals of both populations) had 1,596 mapped markers, and 
those of 'Armking' 1,069 and 'Nectaross' 1,392. As expected, a high proportion of markers (88\%) segregating in either population used for the construction of the 'Big Top' map were the same. The 'Big Top' map (Figure 1) comprised 210 bins distributed along the eight linkage groups of the Prunus map (G1 to G8), spanning a genetic distance of $447.0 \mathrm{cM}$ (Table 1). The 'Armking' map had 126 bins distributed through 9 groups, as markers from G1 could not be joined as expected from the Prunus reference map and were split into two groups (Figure 2). These nine groups summed a total genetic distance of $450.0 \mathrm{cM}$ (Table 1). For the 'Nectaross' genetic map, 94 bins coalesced into the expected eight linkage groups (Figure 3) for a total genetic distance of $320.4 \mathrm{cM}$ (Table 1). The nearly double number of bins found in the 'Big Top' map compared to the other two is a logical consequence of the higher population size that allowed detection of more recombination events. Linkage maps built for the three parents, $\mathrm{Bt}, \mathrm{Nr}$ and $\mathrm{Ak}$ presented good collinearity with the 2.0 version of the peach reference genome and were syntenic to the reference Prunus map based on the ' $\mathrm{T} \times \mathrm{E}$ ' population (Donoso et al. 2015). The only exception was a fragment of $15.8 \mathrm{cM}$ between markers snp_6_5294415 and SNP_IGA_618376, in the proximal end of G6 of the Ak map (Figure 2) that had an inverted order, which seems attributable to imprecise mapping positioning due to the large gap without markers $(28.8 \mathrm{cM})$ that connects this fragment to the rest of the chromosome.

\section{Phenotyping}

Data distribution for each trait was very similar across seasons in both Bt $\times$ Ak (Figure 1S) and $\mathrm{Bt} \times \mathrm{Nr}$ (Figures 1S, 2S and Table 2S). A substantial percentage of the characters (44.4\%) did not follow a normal distribution in different populations or years. Gumminess was the only character that was normally distributed across populations and seasons, MD was not normal in all cases, and the remaining traits adjusted to normality only at certain times.

The Spearman correlation values (Table 3S) for the same character between years were very high for MD (0.89 and 0.78 for Bt×Ak and Bt×Nr, respectively) and much lower for the rest. Only FL3d and FL5d had positive and highly significant values, with the exception of FL5d (0.26) in Bt $\times \mathrm{Nr}$. Hardness was also positively correlated between years in Bt×Ak but negative and non-significant in Bt $\times \mathrm{Nr}$. When looking for correlations between different traits in the same year, these were significant and positive for FL3d and FL5d for both years and populations, and negatively correlated with MD in all eight possible cases, although only significantly in five of them. Some characters, such as hardness, gumminess and chewiness, correlated positively and steadily over years and populations, whereas the correlation for the rest was much more erratic.

\section{QTL analysis}

With the maps of each parent of the $\mathrm{Bt} \times \mathrm{Ak}$ and $\mathrm{Bt} \times \mathrm{Nr}$ progenies we found 20 QTLs: six in 'Armking', three in 'Nectaross', six in 'Big Top (Ak)', two in 'Big Top (Nr)' and three for the 'Big Top' map taking the data from both populations (Table 2). Considering the QTLs that were consistent in at least one of the 
three parents (in the different versions of $\mathrm{Bt}$ that were consistent at least once), we found eight: qP-MD5, qP-FL3d5, qP-FL5d5 in Bt, qP-MD4, qP-MD6, qP-FL5d4 and qP-Har4 in Ak and qP-MD4 in Nr. The analysis using the integrated maps of both Bt $\times \mathrm{Ak}$ and $\mathrm{Bt} \times \mathrm{Nr}$ progenies yielded similar results (Table $4 \mathrm{~S}$ ), with the detection of 32 QTLs, 11 more than with the parental maps, and with all new QTLs found only one year, except for qP-FL3d4, qP-Gum4 and qP-Har5 that were significant both years in Bt×Ak. None of the QTLs detected had a large increase in LOD and $\mathrm{R}^{2}$ when compared to the results obtained with the parental maps, whereas such an increase would be expected for QTLs heterozygous in both parents.

Consistent QTLs localized in a few positions for each parental map, usually coinciding with the location of the QTL(s) for MD (Table 2, Table 5S, Figure1-3). In the 'Big Top' maps all QTLs located at the same region of G5, and similar patterns occurred in 'Armking', with two MD QTLs located on G4 and G6, like all remaining QTLs. This was also the case for 'Nectaross', where a major QTL for MD explaining much of the phenotypic variance $\left(\mathrm{R}^{2}=60-87 \%\right)$ was on $\mathrm{G} 4$, and all other QTLs found in this population for other characters mapped to this position. A few exceptions were identified with the integrated maps (Table 4S), such as three QTLs for Resilience (qP-Res3), Gumminess (qP-Gum1) and Cohesiveness (qP-Coh1) in $\mathrm{Bt} \times \mathrm{Ak}$ and one for FL5d (qP-FL5d1) in Bt $\times \mathrm{Nr}$ that mapped to other linkage groups, but they were detected in only one year.

The MD QTLs had different effects depending on the alleles carried by the parents of the two crosses studied. One allele of 'Armking' for qP-MD4 when homozygous reduced the maturity date by 11.5-15.5 days compared with the heterozygote for the other allele, whereas for the same QTL, one allele of 'Nectaross' extended the maturity date from 21.0-32.0 days (Table 2). MD was also strongly associated with the FL character, often resulting in QTLs for FL3d, FL5d or both being at the same position as those found for MD. The effects of qP-MD4 and qP-MD5 were to increase firmness loss in the early maturing genotypes and to decrease firmness loss, i.e. producing a SMF effect, in the late maturing genotypes. Nevertheless, this did not occur in qP-MD6, where the QTL was not associated with the firmness loss character.

When looking for QTLs for the textural parameters obtained with TPA we found that these traits are mainly governed by the same loci as for firmness loss or maturity date QTLs. The majority of these QTLs were found in the maps of each parent in only one of the two years studied (Table 2) with the exception of a QTL in G4 for Hardness (qP-Har4) coinciding with the position of other QTLs for MD and FL.

The search for genes similar to the protein sequence to the NAC transcription factor candidate gene for $M D$ (Pirona et al. 2013) allowed the identification of 61 genes with high similarity (p-value $<10^{-24}$ ) distributed along the whole peach genome. Only one of them (Prupe.5G006200) fell in the region of 3.3 $\mathrm{Mb}$ defined by the markers SNP_IGA543179 and SNP_IGA_557566 encompassing qP-MD5, and none were found on the qP-MD6 region of 2.3 Mb defined by markers snp_6_5294415 and SNP_IGA_611891 (Table 6S). 


\section{Discussion}

We studied the variability for SMF with different measurements, mainly the loss of firmness during the postharvest process, and a set of fruit texture parameters measured with the texturometer at the time of harvest. The parents and progeny of two populations were measured: crosses between 'Big Top', a model variety for SMF, and the two cultivars 'Armking' and 'Nectaross', having very distant maturity dates but both with typical melting (MF) behavior. For the inheritance analysis we developed linkage maps of these two populations. As in other peach maps with similar marker densities (Eduardo et al. 2013; MartínezGarcía et al. 2013; Donoso et al. 2015), the maps of the parents (Bt, Ak and Nr) had extensive fragments without segregating markers, suggesting the presence of ample genomic regions identical by descent. These regions can be estimated as 100 minus the coverage of the genome (see Table 1) and accounted for $35-49 \%$ of the total physical distance depending on the map. Concentration of 1:2:1 segregating markers at specific genomic regions also indicates the regions where both parents were heterozygous, which ranged between $8 \%$ and $16 \%$ of the genome of the two populations used. Genes/QTLs located at these regions may also be heterozygous in both parents, which has to be taken into account for the genetic analysis. A Bt map has recently been obtained by Zeballos et al. (2016) using also the IPGI 9k Illumina SNP chip. This map was very similar to the one we produced with the exception that we could use almost four times more markers (1,596 vs. 405) for its construction. One of the main reasons for this improvement is that we followed a mapping approach that allowed integration of the markers segregating 1:2:1 and those with skewed segregation ratios, which improved the marker density, mapping accuracy, and also made it possible to identify additional map regions, resulting in a better physical coverage $65 \%$ vs. $40 \%)$.

Of the parameters used to measure the SMF character, the percentage of firmness loss (FL) seems the most efficient. It is noteworthy to mention, however, that fruit firmness is not equivalent to fruit texture but rather is a classical feature of it, with several studies in peaches and apples showing that this parameter is very well correlated to texture as perceived by consumers (Harker et al., 2002; Harker et al., 2006; Giné-Bordonaba et al., 2016). FL measures the character according to SMF definition (a slower process of fruit softening after the field maturity stage than the MF types), as exemplified by the evolution of the FL parameter in the parents used, with a steady decay in the typically MF 'Armking' and 'Nectaross', and a delayed firmness loss in 'Big Top' (Figure 4). In contrast with these results, the SMF signature was not detected when analyzing the FL evolution between 'Nectaross' and 'Big Top', among other cultivars, by Reig et al. (2017). These authors measured FL under different conditions than those of our study since they assessed on-tree firmness loss over sequential harvests as well as in fruit cold stored at $10{ }^{\circ} \mathrm{C}$. Discrepancies between this and the above-mentioned study are likely related to these different measurements; for example, an altered ripening pattern due to an atypical loss of firmness occurs when peaches are cold stored (Giné-Bordonaba et al. 2016).

FL measurements detected QTLs that each explained a substantial part of the variability (20-35\%), although they were not as reproducible as those found with the MD character. Part of this may have been caused by the small size of the populations used, particularly of $\mathrm{Bt} \times \mathrm{Nr}$, so larger populations are needed for accurate measurement of the character. In addition, the spring-summer climatic conditions of 2013 
and 2014 were extremely different in the region of Lleida. In 2013 temperatures were atypical, with strong oscillations, being on average the lowest since 1997 and with unusually high rainfall in July, whereas 2014 was closer to average. As a consequence, maturity times were substantially different, much later in 2013 than in 2014: 14 days later in $\mathrm{Bt} \times \mathrm{Ak}$ and 13 in $\mathrm{Bt} \times \mathrm{Nr}$ on average. This is one possible explanation for the low correlations found in some of the firmness and texture-related traits between years and the heterogeneity in the estimation of certain characters for some years leading to a less accurate QTL analysis. The fact that MD shows a very high correlation between years $(0.78-0.89)$ indicates that the criteria employed for harvest date determination were adequate. The other characters measured with the texturometer were less reliable. QTLs were not consistent across years and, when detected, they generally fell within the same regions as the FL and MD characters, overall providing little information.

Our results detected essentially three regions of the genome on G4, G5 and G6, where genes involved in maturity time and flesh firmness consistently mapped. All had a QTL explaining much of the variability for the maturity date character and all had been reported previously for peach and other Prunus. The major QTL in the central part of G4 (qP-MD4) that we identified has been repeatedly reported by other authors in peach (Eduardo et al. 2011; Pirona et al. 2013; Verde et al. 2002) and in other Prunus such as almond, cherry and apricot (Dirlewanger et al. 2012; Sánchez-Pérez et al. 2007; Donoso et al. 2016). In certain crosses (Eduardo et al. 2011; Pirona et al. 2013) it has been mapped as a single major gene $(M D / m d)$ on $\mathrm{G} 4$. This same region contains the slow ripening $(\mathrm{Sr} / \mathrm{sr})$ gene, and it has been hypothesized that the $s r$ allele determining the SR character is one allele of $M D$ (Eduardo et al. 2015; Núñez-Lillo et al 2015). The QTL on G6 (qP-MD6) has also been identified by Dirlewanger et al. (2012) in a peach F2 population ('Jalousia' $\times$ 'Fantasia'; $\mathrm{J} \times \mathrm{F}$ ) explaining a large proportion (15.7-30.2\%) of the phenotypic variability for this character. Finally, a QTL on a similar region of G5 to where we mapped qP-MD5 was also found by Dirlewanger et al. (2012) on $\mathrm{J} \times \mathrm{F}$, and by Zeballos et al. (2015) although, in the former, it was not consistent over the years.

All QTLs for the firmness loss measurements fell within the same chromosomal regions as qP-MD4 and qP-MD5 and were detected on the maps of the parents that segregated for these QTLs ('Armking' and 'Nectaross' for qP-MD4 and 'Big Top' for qP-MD5), although they were identified with lower LOD scores than MD QTLs and in certain cases (in 2013 for FL3d5 and FL5d5 in Bt(Ak) and the same year for FL3d4 in Ak) were not consistent between the two years studied. The direction of the effects of these two characters was that late maturing fruit had slower firmness loss and vice-versa, which may be related to the observation of Giné-Bordonaba et al. (2016) on the lower capacity of late harvest peach fruit to produce ethylene. Similar results were obtained for qP-MD4 in relation to FL by Salgado et al. (2014). However, no QTLs for FL were associated with qP-MD6 in ‘Armking'.

Two possible factors may explain the observed correlation between MD and SMF. One is that the environment determines that fruit of a tree that matures several weeks after another (with a longer period of attachment to the tree, and hence of exposure to its surrounding environment) may be at a different physiological maturity stage therefore determining a slower postharvest softening process. The second is that there is a common inheritance for these two characters where the same genes, or genes that are in the same region as those that determine maturity date in qP-MD4 and qP-MD5, are also involved in the 
postharvest ripening/softening process. Both factors may also act together and they are difficult to separate, but although the former may have an effect on the final result, this seems to be of minor importance considering that cultivars that are in the extremes of the production season of peach often have very similar postharvest behavior. This is the case for 'Armking' and 'Nectaross', maturing with about 40 days difference and having similar FL parameters, or for 'Big Top', that, being the model for SMF, has a relatively early maturity time (first part of July under Lleida conditions). For the inheritance side, Eduardo et al. (2011) attributed the accumulation of QTLs for various fruit characters (fruit weight, skin color, soluble solids content, acidity) on the central part of G4 to a pleiotropic effect of the $M D$ gene. In addition, Eduardo et al. (2015) identified the position of the $\mathrm{Sr}$ gene, that determines fruits that never ripen or soften, at the same place as $M D$, and Núñez-Lillo et al. (2015) found that the $s r$ allele that determines this character co-maps with a large deletion at the position of the Prupe.4G186800 NAC transcription factor gene that Pirona et al. (2013) identified as a possible candidate for $M D$. These observations are compatible with $M D$ having different alleles that determine the speed of the maturation process, or even its arrest as in the case of $S r$, a process that determines the maturity stage in the field, with the "slow" alleles or allele combinations maturing later than the "fast" ones. This same process may continue after harvest and determine the speed of the softening process, where again the slow or fast alleles would determine a longer or shorter shelf-life of the fruit.

While we noted the association between MD and FL on G4 in the progenies analyzed, it is clear that slight differences in softening rates may not be perceptible in practice and that a certain threshold has to be reached to be identified as having an impact on shelf-life, as with 'Big Top'. The difference between 'Big Top' and the other MF cultivars may be due to the presence of the large QTL on G5 for MD and FL. This QTL has not been found in other peach progenies with the already mentioned exception of 'Jalousia' $\times$ 'Fantasia' cross (Dirlewanger et al. 2012), where the QTL had a smaller effect compared with ours and had a non-consistent behavior pattern. A QTL on G5 reported by Zeballos et al. (2016) for flesh firmness in the Bt map of a 'Big Top' $\times$ 'Venus' cross, seems to co-map with the one we detected, although these authors did not provide information on maturity date. Overall these data confirm the presence of a QTL for $\mathrm{MD}$ and FL on the G5 genomic region, with some inconsistencies in our case that we attribute to the small size of $\mathrm{Bt} \times \mathrm{Nr}$ and the contrasting climate conditions in 2013 and 2014. The allele combination of qP-MD5 in 'Big Top' or the interaction between the alleles of qP-MD4 and qP-MD5 may be responsible for the SMF phenotype of this cultivar. In fact, the individuals with the most favorable genotype for the SMF trait, based on the closest markers to the qP-FL and qP-MD loci (SNP_IGA_551853 in qP-MD5 and SNP_IGA_409351 in qP-MD4), had an average FL3d=24.9 and FL5d=48.5, whereas the rest of the population had averages of FL3d=41.5 and FL5d=62.4, both significantly higher ( $\mathrm{t}$ test with $\mathrm{p}<0.01$ ).

A consequence of the suggested model of action would be that the SMF phenotype could only be found in late maturing individuals. This contradicts the relatively early-mid season maturity time of 'Big Top', about two weeks later than 'Armking' and one month before 'Nectaross'. A possible explanation could be the presence of other genes that affect maturity time but not the maturation or softening processes themselves. An example would be the qP-MD6, explaining approximately $30 \%$ of the variability of this character in 'Armking' with no apparent effect on FL. Selection for early alleles of this QTL may produce 
varieties that mature early and have the SMF trait. There are some examples of this in the Bt $\times A k$ population, where plants \#18, 68, 70 and 78, bearing the optimal marker genotypes for the SMF character (qP-MD4 and qP-MD5) and the early maturing genotype for the closest marker to qP-MD6 (homozygous for SNP_IGA_605027), also had a similar maturity time to 'Big Top' both seasons and comparable, in some cases with even slower, FL than 'Big Top' in both years (see Table 7S). A possible explanation for these results is that the genes responsible for qP-MD4 and qP-MD5 have similar functions, differing from the gene(s) in qP-MD6. Previous evidence of a NAC transcription factor as a strong candidate gene for qP-MD4 (Pirona et al. 2013), along with our observation that the genomic region of qP-MD5 and not that of qP-MD6 contains NAC transcription factors (Table 6S), indicates these factors may be potentially involved in the determination of qP-MD4 and qP-MD5 but not in qP-MD6. Further studies are required to evaluate the possible implication of the NAC genes identified in the genomic region of qP-MD5 in the expression of MD and FL.

The region of $\mathrm{qP}-\mathrm{MD} 5$ overlaps the position of the gene responsible for the acid vs. subacid fruit $(D / d)$ character (Lambert et al. 2016). 'Big Top' is heterozygous $(D d)$ and we placed this gene at its expected map position (data not shown) in the proximal end of G5 (between markers SNP_IGA_544961 and SNP_IGA_545261). The $D$ allele, responsible for the subacid trait, was in coupling with the allele of qPMD5 that enhances the SMF character, resulting in a high proportion of plants being SMF and subacid, i.e., $16(67 \%)$ of the 24 that had the optimal marker genotypes for SMF at qP-MD4 and qP-MD5 (see Table 7S) were subacid. This suggests that the use of 'Big Top' to transfer both characters to its progeny would be a good breeding strategy. Conversely, using parents with recombinant gametes may result in a small number of progeny having both characters at the same time.

Given that the combination of the different genes involved, including inter and intralocus interactions, determines the final phenotype, knowledge of the more precise locations of these QTLs is needed. This means analysing adequate segregating populations, where tightly-linked markers diagnostic to the important QTLs can be identified and validated. At the moment, there is information on the high heritability of the MD character (de Souza et al. 1998; Fresnedo-Ramírez et al. 2016) and the detailed position of the qP-MD4, with a marker based on the candidate gene (Meneses et al. 2016). Additionally, in this paper we have identified the qP-MD5 QTL as a key factor for SMF, the qP-MD6 that may modulate the maturity date, and we also provide a reasonable measurement of the SMF character based on the evolution of firmness loss (FL) during postharvest storage. Overall, this information is indispensable to fully understand the genetics of postharvest behavior and establish a marker-informed breeding procedure for improvement of this crucial character in peach.

\section{Data archiving statement}

Genetic linkage maps and phenotypic data will be submitted to the Genome Database for Rosaceae (www.rosaceae.org). 


\section{Bibliography}

Altschul, SF, Thomas LM, Alejandro AS, Jinghui Z, Zheng Z, Webb M, David JL (1997) Gapped BLAST and PSI-BLAST: a new generation of protein database search programs. Nucleic Acids Res 25:3389-3402

Bassi D, Monet R (2008) Botany and taxonomy. In: DR Layne and D Bassi (eds) The Peach: Botany, production and uses. CABI, Wallingford, UK, pp 1-36

Begheldo M, Manganaris GA, Bonghi C, Tonutti P (2008) Different postharvest conditions modulate ripening and ethylene biosynthetic and signal transduction pathways in Stony Hard peaches. Postharvest Biol Tec 48:84-91

Bourne, M (2002) Food texture and viscosity. 2nd edn. Academic Press, San Diego

de Souza VA, Byrne DH, Taylor JF (1998) Heritability, genetic and phenotypic correlations, and predicted selection response of quantitative traits in peach: II. An analysis of several fruit traits. J Amer Soc Hortic Sci 123:604-611

Dirlewanger E, Quero-García J, Le Dantec L, Lambert P, Ruiz D, Dondini L, Illa E, Quilot-Turion B, Audergon JM, Tartarini S, Letourmy P, Arús P (2012) Comparison of the genetic determinism of two key phenological traits, flowering and maturity dates, in three Prunus species: peach, apricot and sweet cherry. Heredity 109:280-292

Donoso JM, Eduardo I, Picañol R, Batlle I, Howad W, Aranzana MJ, Arús P (2015). High-density mapping suggests cytoplasmic male sterility with two restorer genes in almond $\times$ peach progenies. Hortic Res 2:15016

Donoso JM, Picañol R, Serra O, Howad W, Alegre S, Arús P, Eduardo I (2016) Exploring almond genetic variability useful for peach improvement: Mapping major genes and QTLs in two inter-specific almond $\times$ peach populations. Mol Breeding 36:16

Doyle JJ, Doyle JL (1990) Isolation of plant DNA from fresh tissue. Focus 12:13-15

Eduardo I, Chietera G, Pirona R, Pacheco I, Troggio M, Banchi E, Bassi D, Rossini L, Vecchietti A, Pozzi C (2013) Genetic dissection of aroma volatile compounds from the essential oil of peach fruit: QTL analysis and identification of candidate genes using dense SNP maps. Tree Genet Genomes 9:189-204

Eduardo I, Pacheco I, Chietera G, Bassi D, Pozzi C, Vecchietti A, Rossini L (2011) QTL analysis of fruit quality traits in two peach intraspecific populations and importance of maturity date pleiotropic effect. Tree Genet Genomes 7:323-335

Eduardo I, Picañol R, Rojas E, Batlle I, Howad W, Aranzana MJ, Arús P (2015) Mapping of a major gene for the slow ripening character in peach: co-location with the maturity date gene and development of a candidate gene-based diagnostic marker for its selection. Euphytica 205:627-636

Fresnedo-Ramírez J, Frett TJ, Sandefur PJ, Salgado-Rojas A, Clark JR, Gasic K, Peace CP, Anderson N, Hartmann TP, Byrne DH, Bink MCAM, Weg E, Crisosto CH, Gradziel TM (2016) QTL mapping and breeding value estimation through pedigree-based analysis of fruit size and weight in four diverse peach breeding programs. Tree Genet Genomes 12:1-18

Ghiani A, Negrini N, Morgutti S, Baldin F, Nocito FF, Spinardi A, Mignani I, Bassi D, Cocucci M (2011) Melting of 'Big Top' nectarine fruit: some physiological, biochemical, and molecular aspects. J Amer Soc Hortic Sci 136:61-68 
Giné-Bordonaba J, Cantín CM, Echeverría G, Ubach D, Larrigaudière C (2016). The effect of chilling injury-inducing storage on qualty and consumer acceptance of different Prunus persica cultivars. Postharvest Biol Tec 115:38-47

Gu C, Wang L, Wang W, Zhou H, Ma BQ, Zheng HY, Fang T, Ogutu C, Vimolmangkang S, Han YP (2016) Copy number variation of a gene cluster encoding endopolygalacturonase mediates flesh texture and stone adhesion in peach. J Exp Bot 67:1993-2005

Haji T, Yaegaki H, Yamaguchi M (2001) Changes in ethylene production and flesh firmness of melting, nonmelting and stony hard peaches after harvest. J Jpn Soc Hortic Sci 70:458-459

Haji T, Yaegaki H, Yamaguchi M (2005) Inheritance and expression of fruit texture melting, non-melting and stony hard in peach. Sci Hortic 105:241-248

Harker FR, Maindonald J, Murray SH, Gunson FA, Hallett IC, Walker SB (2002) Sensory interpretation of instrumental measurements 1: texture of apple fruit. Postharvest Biol Technol 24: 225-239

Harker FR, White A, Gunson FA, Hallett IC, De Silva HN (2006) Instrumental measurement of apple texture: A comparison of the single-edge notched bend test and the penetrometer. Postharvest Biol Technol 39: 185-192.

Hayama H, Tatsuki M, Ito A, Kashimura Y (2006) Ethylene and Fruit softening in the stony hard mutation in peach. Postharvest Biol Tec 41:16-21

Iglesias I (2012) Producción, consumo e innovación varietal en el melocotón. Alimentación, equipos y tecnología 268:25-31. ISSN 0212-1689

Iglesias I, Echeverria G (2009) Differential effect of cultivar and harvest date on nectarine colour, quality and consumer acceptance. Sci Hortic 120:41-50

Lambert P, Campoy JA, Pacheco I, Mauroux JB, Da Silva Linge C, Micheletti D, Bassi D, Rossini L, Dirlewanger E, Pascal T, Troggio M, Aranzana MJ, Patocchi A, Arús P (2016) Identifying SNP markers tightly associated with six major genes in peach [Prunus persica (L.) Batsch] using a high-density SNP array with an objective of marker-assisted selection (MAS) Tree Genet Genomes 12:121

Lander ES, Green P, Abrahamson J, Barlow A, Daly MJ, Lincoln SE, \& Newburg L (1987) MAPMAKER: An interactive computer package for constructing primary genetic linkage maps of experimental and natural populations. Genomics 1:174-181

Lester DR, Sherman WB, Atwell BJ (1996) Endopolygalacturonase and the melting flesh (M) locus in peach. J Amer Soc Hortic Sci 121:231-235

Martínez-García PJ, Parfitt DE, Ogundiwin EA, Fass J, Chan HM, Ahmad R, Lurie S, Dandekar A, Gradziel TM, Crisosto CH (2013) High density SNP mapping and QTL analysis for fruit quality characteristics in peach (Prunus persica L.). Tree Genet Genomes 9: 19-36

Meneses C, Ulloa-Zepeda L, Cifuentes-Esquivel A, Infante R, Cantin C, Batlle I, Arús P, Eduardo I (2016) A codominant diagnostic marker for the slow ripening trait in peach. Mol Breeding 36:77

Nuñez-Lillo G, Cifuentes-Esquivel A, Troggio M, Micheletti D, Infante R, Campos-Vargas R, Orellana A, Blanco-Herrera F, Meneses C (2015) Identification of candidate genes associated with mealiness and maturity date in peach [Prunus persica (L.) Batsch] using QTL analysis and deep sequencing. Tree Genet Genomes 11:86

Pan L, Zeng WF, Niu L, Lu ZH, Liu H, Cui GC, Zhu YQ, Chu JF, Li WP, Fang WF, Cai ZG, Li GH, 
Wang ZQ (2015) PpYUC11, a strong candidate gene for the stony hard phenotype in peach (Prunus persica L. Batsch), participates in IAA biosynthesis during fruit ripening. J Exp Bot 66:7031-7044

Peace CP, Crisosto CH, Gradziel TM (2005) Endopolygalacturonase: a candidate gene for Freestone and Melting flesh in peach. Mol Breeding 16:21-31

Pirona R, Eduardo I, Pacheco I, Da Silva Linge C, Miculan M, Verde I, Tartarini S, Dondini L, Pea G, Bassi D, Rossini L (2013) Fine mapping and identification of a candidate gene for a major locus controlling maturity date in peach. BMC Plant Biol 13:166

Reig G, Alegre S, Cantín CM, Gatius F, Iglesias I (2017) Tree ripening and postharvest firmness loss of eleven commercial nectarine cultivars under Mediterranean conditions. Sci Hortic 219:335-343

R Core Team (2015). R: A language and environment for statistical computing. R Foundation for Statistical Computing, Vienna, Austria. URL http://www.R-project.org/

Ramina A, Tonutti P, McGlasson B (2008) Ripening, nutrition and postharvest physiology. In: The Peach: Botany, production and uses. DR Layne and D Bassi (eds). CABI (Wallingford, UK) pp. 550-574 Ramming DW (1991) Genetic control of a slow-ripening fruit trait in nectarine. Can J Plant Sci 71:601603

Salgado A, Clark J, Sandefur P, Frett T, Peace C (2014) Softening rate and ethylene fruit production of different flesh textures of Arkansas peach and nectarine germplasm. American Society for Horticultural Science congress, Orlando, FL, USA, july 27th to august 1st, 2014.

Sánchez-Pérez R, Howad W, Dicenta F, Arús P, Martínez-Gómez P (2007) Mapping major genes and quantitative trait loci controlling agronomic traits in almond. Plant Breeding 125:1-9

Van Ooijen JW (2009) MapQTL ® 6, Software for the mapping of quantitative trait loci in experimental populations of diploid species. Kyazma B.V., Wageningen, The Netherlands

Verde I, Bassil N, Scalabrin S, Gilmore B, Lawley CT, Gasic K Micheletti D, Rosyara UR, Cattonaro F, Vendramin E, Main D, Aramini V, Blas AL, Mockler TC, Bryant DW, Wilhelm L, Troggio M, Sosinski B, Aranzana MJ, Arús P, Iezzoni A, Morgante M, Peace C (2012) Development and evaluation of a 9K SNP array for peach by internationally coordinated SNP detection and validation in breeding germplasm. PloS One 7:e35668

Verde I, Quarta R, Cedrola C, Dettori MT (2002). QTL analysis of agronomic traits in a BC1 peach population. Acta Hortic 592:291-297

Zeballos JL, Abidi W, Giménez R, Monforte AJ, Moreno MA, Gogorcena Y (2016) Mapping QTLs associated with fruit quality traits in peach [Prunus persica (L.) Batsch] using SNP maps. Tree Genet Genomes 12:37

Ziosi V, Noferini M, Fiori G, Tadiello A, Trainotti L, Casadoro G, Costa G (2008) A new index based on vis spectroscopy to characterize the progression of ripening in peach fruit. Postharvest Biol Tec 49:319329 
Table 1. Distribution of markers in the linkage groups (G1-G8) of the maps of 'Big Top' (joint data from the $\mathrm{Bt} \times \mathrm{Ak}$ and $\mathrm{Bt} \times \mathrm{Nr}$ populations), 'Armking' and 'Nectaross' for total markers, number of bins, distance in centimorgans and physical coverage

\begin{tabular}{|c|c|c|c|c|c|c|c|c|c|c|}
\hline & & G1 & G2 & G3 & G4 & G5 & G6 & G7 & G8 & Total \\
\hline \multirow{4}{*}{ 'Bigtop’ } & $\begin{array}{l}\text { Mapped } \\
\text { markers }\end{array}$ & 284 & 274 & 282 & 194 & 109 & 169 & 147 & 137 & 1596 \\
\hline & Bins & 40 & 15 & 42 & 25 & 26 & 21 & 19 & 22 & 210 \\
\hline & $\mathrm{cM}$ & 90.3 & 25.9 & 60.0 & 49.1 & 49.3 & 71.0 & 45.2 & 56.2 & 447.0 \\
\hline & Coverage $^{a}$ & 81 & 59 & 96 & 53 & 77 & 50 & 56 & 48 & 65 \\
\hline \multirow{4}{*}{ 'Armking' } & $\begin{array}{l}\text { Mapped } \\
\text { markers }\end{array}$ & 65 & 230 & 92 & 207 & 23 & 144 & 194 & 114 & 1069 \\
\hline & Bins & 17 & 16 & 9 & 16 & 5 & 21 & 26 & 16 & 126 \\
\hline & $\mathrm{cM}$ & $\begin{array}{c}111.2 \\
(72.2+39.0)\end{array}$ & 78.7 & 37.9 & 36.6 & 9.4 & 82.9 & 64.2 & 29.1 & 450.0 \\
\hline & Coverage $^{a}$ & 57 & 68 & 60 & 39 & 6 & 40 & 88 & 49 & 51 \\
\hline \multirow{4}{*}{ 'Nectaross' } & $\begin{array}{l}\text { Mapped } \\
\text { markers }\end{array}$ & 158 & 219 & 213 & 261 & 75 & 243 & 60 & 163 & 1392 \\
\hline & Bins & 12 & 12 & 15 & 15 & 9 & 12 & 4 & 15 & 94 \\
\hline & $\mathrm{cM}$ & 58.4 & 32.2 & 50.5 & 46.3 & 24.2 & 52.9 & 11.7 & 44.2 & 320.4 \\
\hline & Coverage $^{a}$ & 70 & 37 & 80 & 47 & 28 & 71 & 22 & 90 & 56 \\
\hline
\end{tabular}

${ }^{a}$ Coverage: percentage of the total physical distance of each linkage group covered by the markers in its extremes. Large regions ( $>5 \mathrm{Mb}$ ) without any marker were considered as identical by descent and were taken as regions not covered. 
Table 2. QTLs identified in the maps of the parents 'Big Top' (Bt), 'Armking' (Ak) and 'Nectaross' (Nr). Consistent QTLs are marked with an asterisk.

\begin{tabular}{|c|c|c|c|c|c|c|c|c|}
\hline Trait & Parent & QTL & Year & LOD & Nearest marker & $\begin{array}{c}\text { Position } \\
\text { (cM) }\end{array}$ & $\mathbf{R}^{2 \mathbf{a}}$ & $\mathbf{a}^{\mathbf{b}}$ \\
\hline \multirow{2}{*}{ Maturity date } & \multirow{2}{*}{$\mathrm{Bt}(\mathrm{Ak})$} & \multirow{2}{*}{ qP-MD5 ${ }^{c}$} & 2013 & 4.95 & SNP_IGA_588670 & 30.7 & 27.1 & -11.3 \\
\hline & & & 2014 & 6.34 & SNP_IGA_550504 & 9.2 & 32.3 & -8.6 \\
\hline$\%$ firmness loss (day 3 ) & $\mathrm{Bt}(\mathrm{Ak})$ & qP-pFL3d5 & 2014 & 4.58 & SNP_IGA_553456 & 13.1 & 24.5 & 26.9 \\
\hline$\%$ firmness loss (day 5) & $\mathrm{Bt}(\mathrm{Ak})$ & qP-pFL5d5 & 2014 & 3.49 & SNP_IGA_572589 & 20.7 & 19.3 & 18.4 \\
\hline Hardness & $\mathrm{Bt}(\mathrm{Ak})$ & qP-Har5 & 2013 & 5.26 & SNP_IGA_552927 & 11.8 & 28.6 & -4.7 \\
\hline Gumminess & $\mathrm{Bt}(\mathrm{Ak})$ & qP-Gum5 & 2013 & 3.79 & SNP_IGA_552927 & 11.8 & 21.5 & -1.7 \\
\hline Chewiness & $\mathrm{Bt}(\mathrm{Ak})$ & qP-Che5 & 2013 & 3.07 & SNP_IGA_552927 & 11.8 & 17.8 & -2.2 \\
\hline \multirow{2}{*}{$\%$ firmness loss (day 3 ) } & \multirow{2}{*}{$\mathrm{Bt}(\mathrm{Nr})$} & \multirow{2}{*}{$\mathrm{qP}-\mathrm{FL} 3 \mathrm{~d} 5^{\mathrm{c}}$} & 2013 & 3.61 & SNP_IGA_571548 & 18.7 & 30.9 & 26.2 \\
\hline & & & 2014 & 3.43 & SNP_IGA_545261 & 3.1 & 29.1 & 35.7 \\
\hline \multirow{2}{*}{$\%$ firmness loss (day 5) } & \multirow{2}{*}{$\mathrm{Bt}(\mathrm{Nr})$} & \multirow{2}{*}{$\mathrm{qP}-\mathrm{FL} 5 \mathrm{~d} 5^{\mathrm{c}}$} & 2013 & 2.41 & SNP_IGA_571548 & 19.7 & 21.8 & 17.2 \\
\hline & & & 2014 & 4.63 & SNP_IGA_559057 & 10.4 & 37.1 & 24.4 \\
\hline \multirow{2}{*}{ Maturity date } & \multirow{2}{*}{$\begin{array}{c}\mathrm{Bt}(\mathrm{Ak}+ \\
\mathrm{Nr})\end{array}$} & \multirow{2}{*}{$\mathrm{qP}^{-\mathrm{MD5}^{\mathrm{c}}}$} & 2013 & 2.73 & SNP_IGA_551853 & 7.2 & 10.2 & -12.4 \\
\hline & & & 2014 & 4.00 & SNP_IGA_551853 & 7.2 & 14.1 & -14.8 \\
\hline \multirow{2}{*}{$\%$ firmness loss (day 3) } & \multirow{2}{*}{$\begin{array}{c}\mathrm{Bt}(\mathrm{Ak}+ \\
\mathrm{Nr})\end{array}$} & \multirow{2}{*}{ qP-FL3d $5^{c}$} & 2013 & 2.96 & SNP_IGA_572589 & 17.7 & 11 & 15.5 \\
\hline & & & 2014 & 8.57 & SNP_IGA_553456 & 8.8 & 27.8 & 31.3 \\
\hline$\%$ firmness loss (day 5) & $\begin{array}{c}\mathrm{Bt}(\mathrm{Ak}+ \\
\mathrm{Nr})\end{array}$ & qP-FL5d5 & 2014 & 7.38 & SNP_IGA_572589 & 19.7 & 24.5 & 20.6 \\
\hline \multirow{4}{*}{ Maturity date } & \multirow{4}{*}{ Ak } & \multirow{2}{*}{ qP-MD4* } & 2013 & 10.94 & SNP_IGA_409351 & 36.6 & 50.3 & 15.5 \\
\hline & & & 2014 & 13.98 & SNP_IGA_409351 & 36.6 & 57.6 & 11.5 \\
\hline & & \multirow{2}{*}{ qP-MD6 ${ }^{\mathrm{c}}$} & 2013 & 3.59 & SNP_IGA_605027 & 4.0 & 20.5 & -9.7 \\
\hline & & & 2014 & 5.21 & SNP_IGA_605027 & 4.0 & 27.4 & -7.8 \\
\hline$\%$ firmness loss (day 3) & $\mathrm{Ak}$ & qP-FL3d4 & 2014 & 6.16 & SNP_IGA_409351 & 36.5 & 31.5 & -30.4 \\
\hline \multirow{2}{*}{$\%$ firmness loss (day 5) } & \multirow{2}{*}{ Ak } & \multirow{2}{*}{$\mathrm{qP}-\mathrm{FL} 5 \mathrm{~d} 4^{\mathrm{c}}$} & 2013 & 2.36 & SNP_IGA_401886 & 25.2 & 14 & -15.1 \\
\hline & & & 2014 & 4.84 & SNP_IGA_409351 & 36.5 & 25.7 & -20.9 \\
\hline \multirow{2}{*}{ Hardness } & \multirow{2}{*}{$\mathrm{Ak}$} & \multirow{2}{*}{$\mathrm{qP}-\mathrm{Har} 4^{\mathrm{c}}$} & 2013 & 4.69 & SNP_IGA_409351 & 36.5 & 25.9 & 4.5 \\
\hline & & & 2014 & 6.30 & SNP_IGA_404165 & 33.2 & 32.1 & 8.3 \\
\hline Gumminess & $\mathrm{Ak}$ & qP-Gum4 & 2014 & 4.58 & SNP_IGA_404570 & 34.2 & 24.5 & 3.6 \\
\hline \multirow{2}{*}{ Maturity date } & \multirow{2}{*}{$\mathrm{Nr}$} & \multirow{2}{*}{$\mathrm{qP}-\mathrm{MD} 4^{\mathrm{c}}$} & 2013 & 8.95 & SNP_IGA_409274 & 24.3 & 60.0 & -21.0 \\
\hline & & & 2014 & 20.05 & SNP_IGA_409274 & 24.3 & 86.6 & -32.0 \\
\hline$\%$ firmness loss (day 3 ) & $\mathrm{Nr}$ & qP-FL3d4 & 2013 & 4.45 & SNP_IGA_409274 & 24.3 & 36.6 & 28.0 \\
\hline$\%$ firmness loss (day 5 ) & $\mathrm{Nr}$ & qP-FL5d4 & 2013 & 3.76 & SNP_IGA_409274 & 24.4 & 31.9 & 20.4 \\
\hline
\end{tabular}

$\mathrm{Bt}(\mathrm{Ak})$ : map of Bt obtained with the BtxAk cross; $\mathrm{Bt}(\mathrm{Nr})$ : map of Bt obtained with the BtxAk cross;

$\mathrm{Bt}(\mathrm{Ak}+\mathrm{Nr})$ : map of Bt obtained with the data from BtxAk and Btx Nr

${ }^{\mathrm{a}} \mathrm{R}^{2}$ : percentage of the total phenotypic variance for this trait explained by the QTL

${ }^{\mathrm{b}}$ Additive effects: $\mathrm{a}=\mathrm{H}-\mathrm{B}$, where $\mathrm{H}$ is the heterozygote and $\mathrm{B}$ the homozygote

${ }^{\mathrm{c}}$ Consistent QTLs 


\section{Figure captions}

Fig. 4 Fruit firmness evolution for the parental lines 'Big Top' (Bt). 'Armking' (Ak) and 'Nectaross' (Nr) during a five-day period. A different behavior can be observed between 'Big Top' and the other two cultivars caused by the SMF trait. Firmness values were recorded in Newtons (N). 
Fig. 1 'Big Top' linkage map obtained with all data available from the $\mathrm{Bt} \times \mathrm{Ak}$ and $\mathrm{Bt} \times \mathrm{Nr}$ populations and the positions of the QTLs mapped in this work. Genetic distances in centimorgans are shown on the left and marker names on the right for each linkage group. Marker names have been abbreviated (SA=SNP_IGA_). Each marker corresponds to a bin (i.e. a group of markers with a same genotype for all individuals analyzed). For QTLs bars in red represent QTLs for maturity date and in green for firmness loss. Solid bars are consistent QTLs and empty bars with diagonal lines represent QTLs detected only one year.

G1

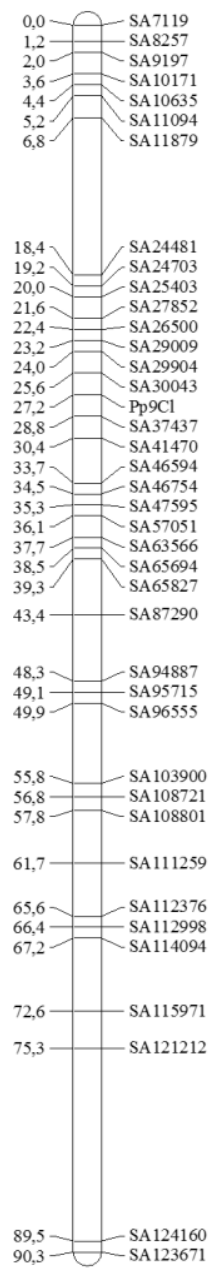

G5

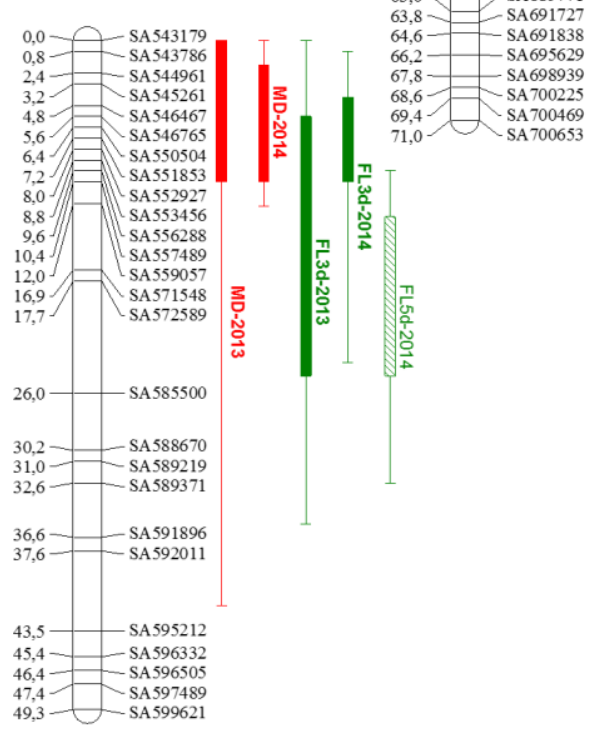

G3

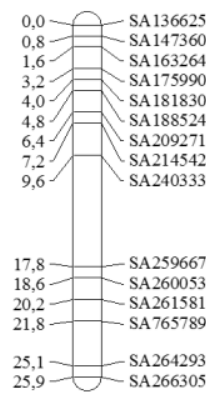

G6

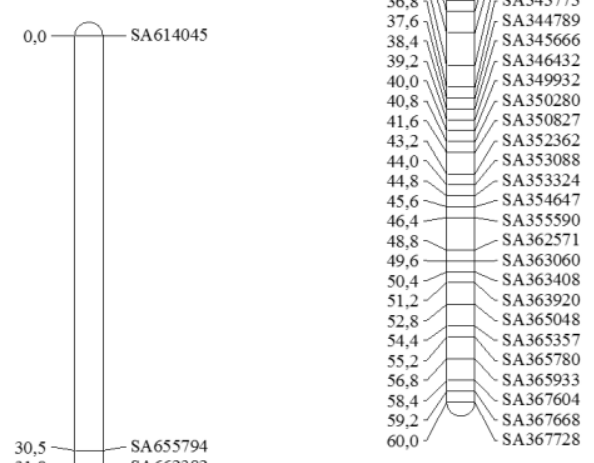

G7

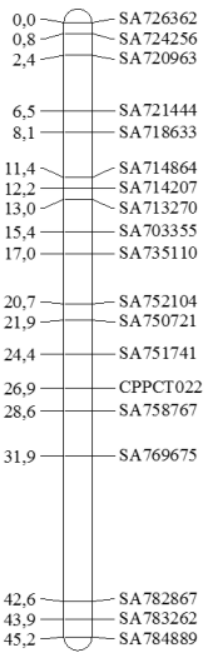

G4

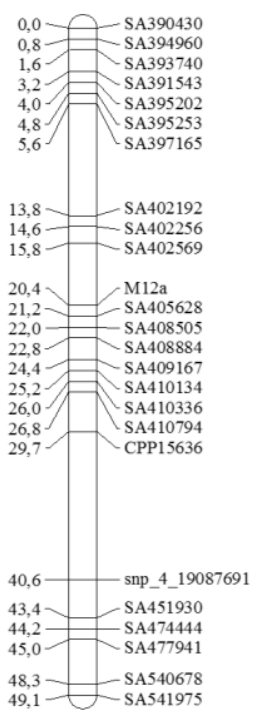

G8

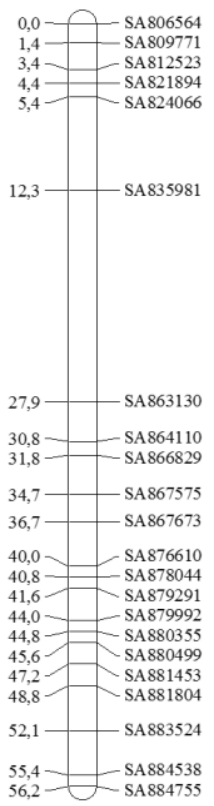


Fig. 2 'Armking' linkage map obtained with positions of the QTLs mapped in this work. Genetic distances in centimorgans are shown on the left and marker names on the right for each linkage group. Marker names have been abbreviated (SA=SNP_IGA_). Each marker corresponds to a bin (i.e. a group of markers with a same genotype for all individuals analyzed). For QTLs bars in red represent QTLs for maturity date, in green for firmness loss and in blue for TPA parameters. Solid bars are consistent QTLs and empty bars with diagonal lines represent QTLs detected only one year

G2

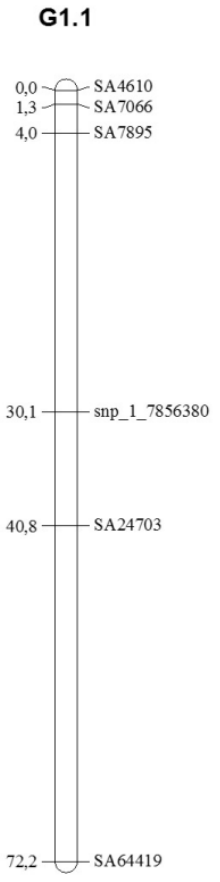

G1.2

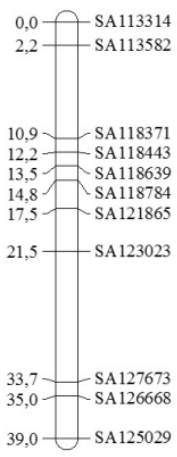

G5
G3

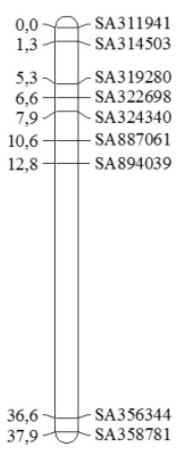

G6
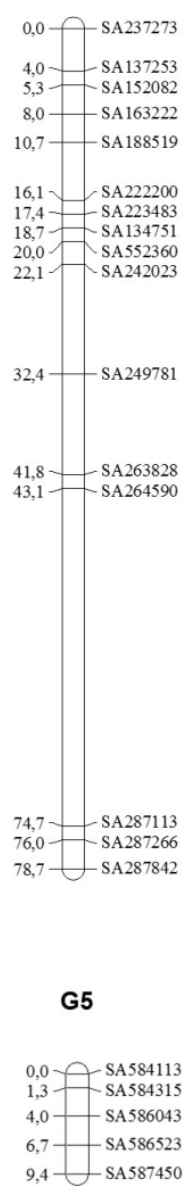

G4

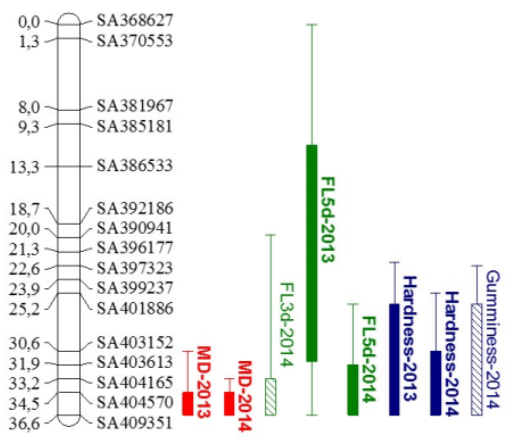

G7

G8

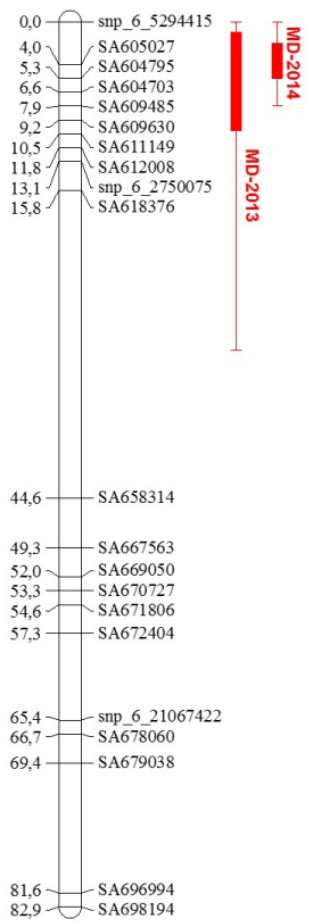

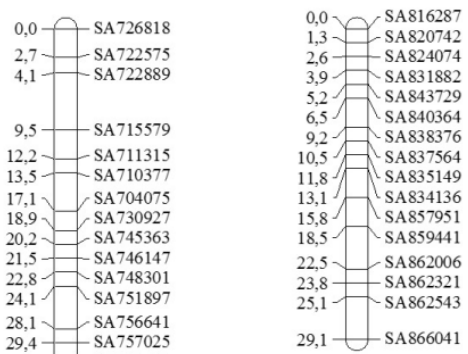


Fig. 3 'Nectaross' linkage map obtained with positions of the QTLs mapped in this work. Genetic distances in centimorgans are shown on the left and marker names on the right for each linkage group. Marker names have been abbreviated (SA=SNP_IGA_). Each marker corresponds to a bin (i.e. a group of markers with a same genotype for all individuals analyzed). For QTLs bars in red represent QTLs for maturity date and in green for firmness loss. Solid bars are consistent QTLs and empty bars with diagonal lines represent QTLs detected only one year.

G1

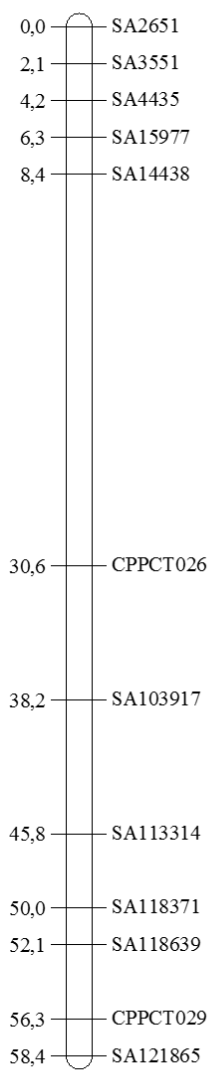

G5

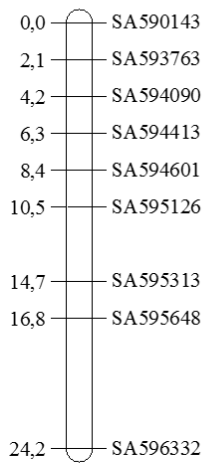

G2
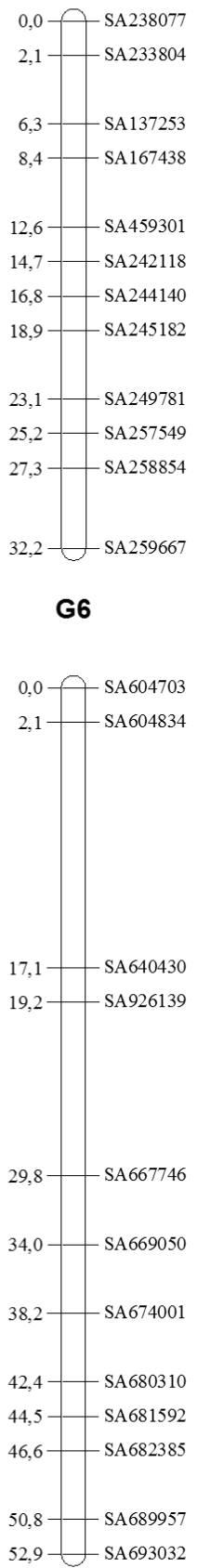

G3

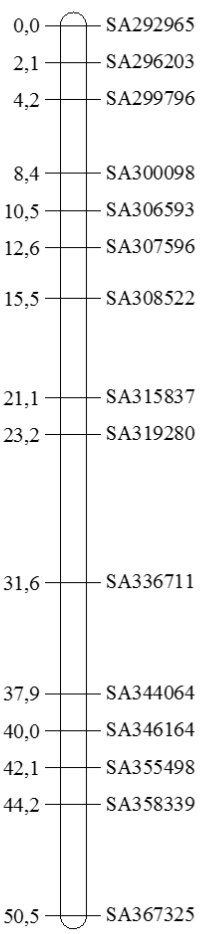

G7

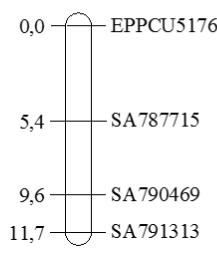

G4

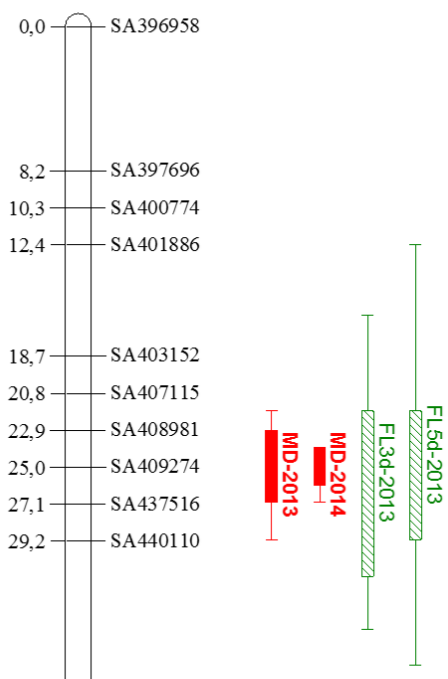

G8

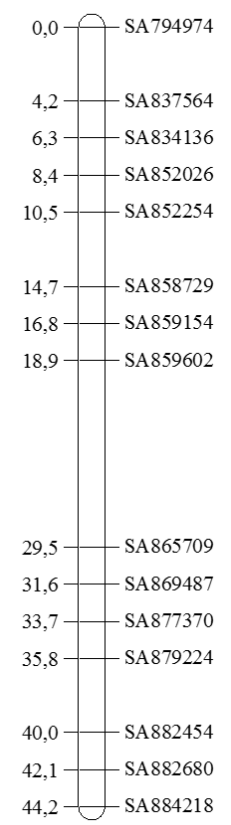


Fig. 4: Changes in fruit firmness during storage at $20^{\circ} \mathrm{C}$ immediately after harvest in the parental lines 'Big Top' (Bt), 'Armking' (AK) and 'Nectaross' ( $\mathrm{Nr}$ ) during a five-day period at $20^{\circ} \mathrm{C}$. A different behaviour can be observed between 'Big Top' and the other cultivars caused by the SMF trait. Firmness values are presented in Newtons ( $N$; mean \pm standard deviation for $\mathrm{n}=10)$.

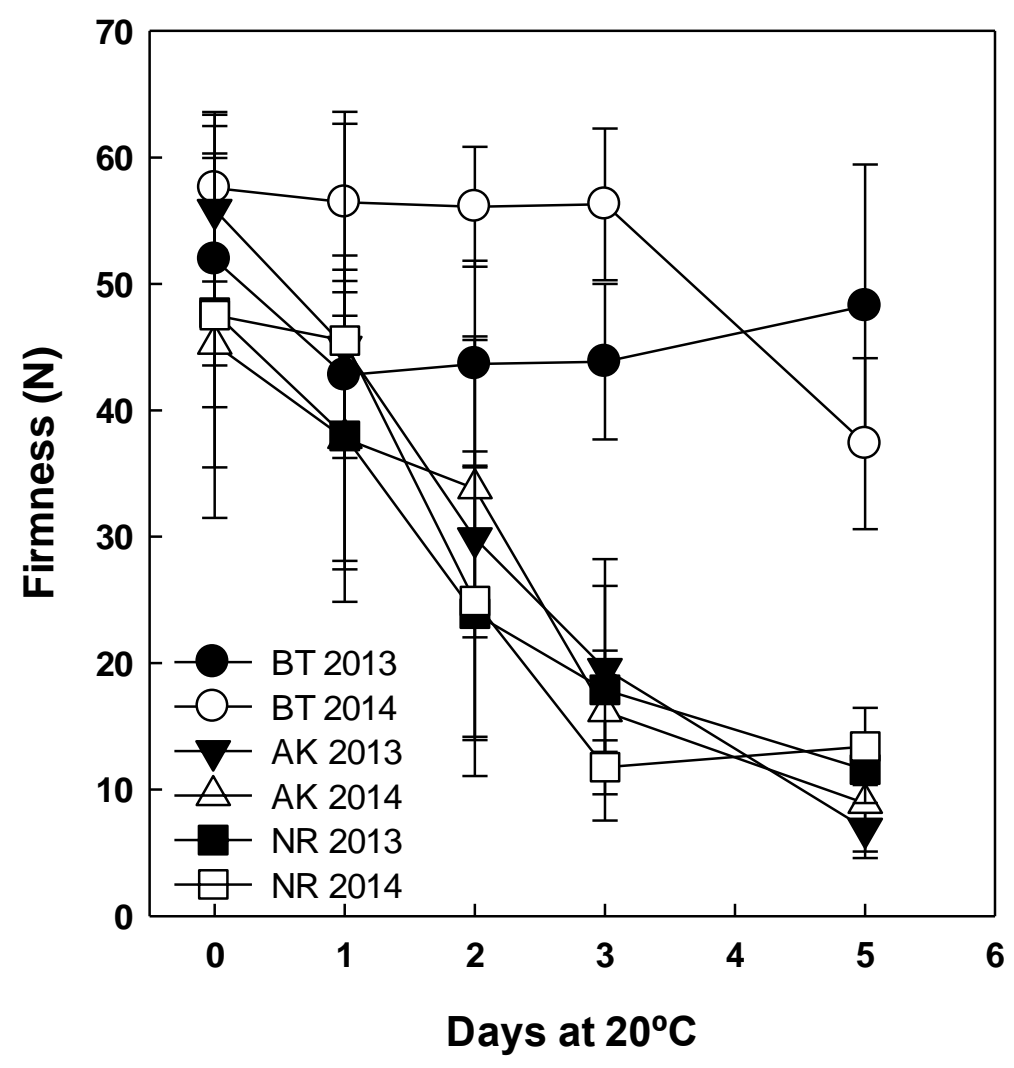


Genetic analysis of the slow melting flesh character in peach

Tree Genetics and Genomes

Octávio Serra, Jordi Giné-Bordonaba, Iban Eduardo, Joan Bonany, Gemma Echeverría, Christian Larrigaudière, and Pere Arús

Corresponding author: Pere Arús

e-mail: pere.arus@irta.cat

Affiliation: IRTA. Centre de Recerca en Agrigenòmica CSIC-IRTA-UAB-UB, Campus UAB, Cerdanyola del Vallès (Bellaterra), 08193 Barcelona, Spain;

Supplementary Tables $1 \mathrm{~S}$ to $6 \mathrm{~S}$ 
Table 1S. Characteristics of the 24 microsatellites used to construct the maps of Bt, Ak and Nr. Details of the map and physical position and origin of the microsatellite can be found in Donoso et al. (2015).

\begin{tabular}{|l|c|c|c|c|}
\cline { 3 - 5 } \multicolumn{2}{c|}{} & \multicolumn{3}{c|}{ Mapped in } \\
\hline Marker & $\begin{array}{c}\text { Linkage } \\
\text { group }\end{array}$ & $\mathrm{Bt}$ & $\mathrm{Ak}$ & $\mathrm{Nr}$ \\
\hline M16a & 1 & $\mathrm{X}$ & & \\
\hline EPPCU5331 & 1 & $\mathrm{X}$ & & \\
\hline EPPCU1945 & 1 & $\mathrm{X}$ & & \\
\hline CPPCT026 & 1 & & & $\mathrm{X}$ \\
\hline BPPCT020 & 1 & $\mathrm{X}$ & & $\mathrm{X}$ \\
\hline CPPCT042 & 1 & & $\mathrm{X}$ & \\
\hline CPPCT029 & 1 & $\mathrm{X}$ & & $\mathrm{X}$ \\
\hline PceGA34 & 2 & & $\mathrm{X}$ & \\
\hline BPPCT007 & 3 & $\mathrm{X}$ & & $\mathrm{X}$ \\
\hline BPPCT039 & 3 & $\mathrm{X}$ & & \\
\hline EPDCU3083 & 3 & $\mathrm{X}$ & & \\
\hline UDP96-008 & 3 & $\mathrm{X}$ & & \\
\hline UDP96-003 & 4 & $\mathrm{X}$ & & $\mathrm{X}$ \\
\hline M12a & 4 & $\mathrm{X}$ & & $\mathrm{X}$ \\
\hline CPP15636 & 4 & $\mathrm{X}$ & & $\mathrm{X}$ \\
\hline EPPCU1775 & 4 & $\mathrm{X}$ & & $\mathrm{X}$ \\
\hline Pacita021 & 5 & $\mathrm{X}$ & & $\mathrm{X}$ \\
\hline EPDCU5183 & 5 & $\mathrm{X}$ & & $\mathrm{X}$ \\
\hline CPSCT012 & 6 & & & $\mathrm{X}$ \\
\hline MA040a & 6 & $\mathrm{X}$ & & $\mathrm{X}$ \\
\hline CPPCT022 & 7 & $\mathrm{X}$ & & \\
\hline CPPCT033 & 7 & & $\mathrm{X}$ & \\
\hline EPPCU5176 & 7 & $\mathrm{X}$ & & $\mathrm{X}$ \\
\hline CPPCT058 & 8 & $\mathrm{X}$ & & \\
\hline
\end{tabular}


Table 2S - Summary of the phenotypic data of 2013 and 2014 for the parents and the mean, minimum, maximum and standard deviation values for the Bt $\times \mathrm{Ak}$ and Bt $\times \mathrm{Nr}$ progenies.

\begin{tabular}{|c|c|c|c|c|c|c|c|c|c|c|c|c|c|c|}
\hline 2013 & \multicolumn{5}{|c|}{ Parental lines } & \multicolumn{6}{c|}{ Bt $\times \mathrm{Nr}$} \\
\hline Trait & 'Bigtop' & 'Armking' & 'Nectaross' & mean & $\min$ & $\max$ & sd & SW test & mean & $\min$ & $\max$ & sd & SW test \\
\hline MD & 189 & 178 & 217 & 183.99 & 169 & 206 & 10.7 & $* * *$ & 216 & 192 & 238 & 13.10 & $* * *$ \\
FLd3 & 15.57 & 62.53 & 65.00 & 43.62 & -11.11 & 78.89 & 23.94 & $* *$ & 40.25 & -4.94 & 78.96 & 22.37 & $\mathrm{~ns}$ \\
FLd5 & 7.08 & 75.70 & 87.61 & 59.01 & 0.6 & 87.03 & 20.05 & $* * *$ & 58.82 & 13.95 & 85.83 & 17.45 & $\mathrm{~ns}$ \\
Springiness & 1.23 & 2.09 & 1.23 & 1.01 & 0.62 & 2.63 & 0.26 & $\mathrm{~ns}$ & 1.16 & 0.77 & 1.44 & 0.12 & $* *$ \\
Hardness & 8.71 & 8.75 & 17.05 & 11.62 & 3.9 & 21.83 & 4.34 & $*$ & 15.54 & 1.98 & 33.47 & 6.69 & $*$ \\
Gumminess & 4.31 & 3.70 & 7.87 & 5.18 & 1.78 & 10.16 & 1.83 & $\mathrm{~ns}$ & 8.55 & 1.44 & 27.01 & 6.42 & $\mathrm{~ns}$ \\
Resilience & 0.72 & 1.04 & 0.84 & 0.81 & 0.16 & 1.48 & 0.26 & $\mathrm{~ns}$ & 0.79 & 0.14 & 1.98 & 0.35 & $\mathrm{~ns}$ \\
Chewiness & 5.29 & 7.71 & 9.70 & 5.25 & 1.1 & 20.12 & 2.59 & $\mathrm{~ns}$ & 10.21 & 1.2 & 33.58 & 8.17 & $\mathrm{~ns}$ \\
Cohesiviness & 0.50 & 0.42 & 0.46 & 0.47 & 0.23 & 0.82 & 0.12 & $*$ & 0.5 & 0.2 & 0.96 & 0.19 & $*$ \\
\hline
\end{tabular}

\begin{tabular}{|c|c|c|c|c|c|c|c|c|c|c|c|c|c|}
\hline \multirow{2}{*}{$\begin{array}{l}2014 \\
\text { Trait }\end{array}$} & \multicolumn{3}{|c|}{ Parental lines } & \multicolumn{5}{|c|}{$\mathrm{Bt} \times \mathrm{Ak}$} & \multicolumn{5}{|c|}{$\mathrm{Bt} \times \mathrm{Nr}$} \\
\hline & 'Bigtop' & 'Armking' & 'Nectaross' & mean & $\min$ & $\max$ & $\mathrm{sd}$ & SW test ${ }^{\mathrm{a}}$ & mean & $\min$ & $\max$ & $\mathrm{sd}$ & SW test ${ }^{\mathrm{a}}$ \\
\hline $\mathrm{MD}$ & 174 & 163 & 202 & 170 & 161 & 184 & 7.52 & $* * *$ & 202 & 177 & 226 & 16.77 & $* * *$ \\
\hline FLd3 & 2.22 & 75.26 & 64.25 & 35.86 & -34.56 & 83.18 & 27.09 & $\mathrm{~ns}$ & 24.47 & -61.23 & 74.68 & 31.78 & ns \\
\hline FLd5 & 35.11 & 71.78 & 80.28 & 58.58 & -2.31 & 90.01 & 20.56 & $* * *$ & 56.62 & 19.80 & 86.38 & 18.73 & ns \\
\hline Springiness & 0.49 & 0.48 & 0.46 & 0.43 & 0.01 & 1.35 & 0.19 & $\mathrm{~ns}$ & 0.46 & 0.37 & 0.62 & 0.06 & ns \\
\hline Hardness & 30.39 & 6.42 & 14.05 & 16.51 & 1.98 & 29.02 & 7.19 & $*$ & 13.21 & 6.54 & 32.28 & 4.31 & ns \\
\hline Gumminess & 15.01 & 1.12 & 3.97 & 6.48 & 0.53 & 16.40 & 3.53 & ns & 3.71 & 1.27 & 14.03 & 2.25 & ns \\
\hline Resilience & 0.46 & 0.08 & 0.15 & 0.27 & -0.29 & 0.68 & 0.15 & ns & 0.17 & -0.01 & 0.53 & 0.10 & $* * *$ \\
\hline Chewiness & 7.38 & 0.54 & 1.82 & 3.21 & 0.02 & 21.54 & 3.01 & $* * *$ & 1.76 & 0.49 & 8.66 & 1.33 & ns \\
\hline Cohesiviness & 0.53 & 0.15 & 0.26 & 0.42 & 0.13 & 1.14 & 0.18 & $* * *$ & 0.29 & 0.14 & 1.06 & 0.15 & ns \\
\hline
\end{tabular}

${ }^{a} \mathrm{p}$-value of the Shapiro-Wilk test for adjustment to a normal distribution: ${ }^{*} \mathrm{p} \leq 0.05 ; * * \mathrm{p} \leq 0.01 ; * * \mathrm{p} \leq 0.001$; ns. non-significant 
Table 3S. Spearman's Rank correlations for Bt $\times \mathrm{Ak}$ and $\mathrm{Bt} \times \mathrm{Nr}$ progenies. Diagonal values shaded in grey represent correlations for the same trait between years. Values below diagonal line represent correlations between traits for 2013 and above the diagonal line are the correlations for 2014 . Asterisks represent the significance of the correlation $(* * \mathrm{p}$-value $<0.01$; $* * * \mathrm{p}$-value $<0.001)$

\begin{tabular}{|c|c|c|c|c|c|c|c|c|c|}
\hline Bt $\times \mathbf{A k}$ & MD & FL3d & FL5d & Springiness & Hardness & Gumminess & Resilience & Chewiness & Cohesiviness \\
\hline MD & $0.89 * * *$ & $-0.64 * * *$ & $-0.49 * * *$ & $0.4 * * *$ & $0.5^{* * *}$ & $0.39 * * *$ & -0.02 & $0.47 * * *$ & -0.17 \\
\hline FL3d & -0.07 & $0.34 * *$ & $0.79 * * *$ & -0.29 & $-0.65 * * *$ & $-0.51 * * *$ & -0.2 & $-50 * * *$ & 0.08 \\
\hline FL5d & -0.14 & $0.75 * * *$ & $0.31 * *$ & $-0.31 * *$ & $-0.59 * * *$ & $-0.49 * * *$ & -0.16 & $-50 * * *$ & 0.05 \\
\hline Springiness & -0.02 & 0.25 & 0.21 & -0.18 & $0.55^{* * *}$ & $0.47 * * *$ & $-0.33^{* *}$ & $0.74 * * *$ & -0.29 \\
\hline Hardness & $0.53 * * *$ & -0.22 & -0.16 & -0.07 & $0.37 *$ & $0.77 * * *$ & 0.17 & $0.81 * * *$ & -0.1 \\
\hline Gumminess & $0.37 * *$ & -0.18 & -0.07 & 0.05 & $0.78 * * *$ & 0.11 & $0.47 * * *$ & $0.91 * * *$ & $0.42 * * *$ \\
\hline Resilience & $0.38 * * *$ & $-0.3^{*}$ & -0.27 & $-0.32 * *$ & $0.37 * *$ & 0.12 & 0.04 & 0.19 & $0.7 * * *$ \\
\hline Chewiness & 0.29 & -0.06 & 0.01 & $0.4 * * *$ & $0.66 * * *$ & $0.9 * * *$ & 0.03 & -0.02 & 0.01 \\
\hline Cohesiviness & $-0.38 * * *$ & 0.13 & 0.21 & 0.11 & $-0.45 * * *$ & 0.14 & $-0.45 * * *$ & 0.17 & -0.03 \\
\hline $\mathrm{Bt} \times \mathrm{Nr}$ & MD & FL3d & FL5d & springiness & Hardness & Gumminess & Resilience & Chewiness & Cohesiviness \\
\hline MD & $0.78 * * *$ & -0.37 & $-0.41 * *$ & -0.11 & -0.23 & $-0.39 *$ & -0.2 & $-0.39 * * *$ & $-0.4 * *$ \\
\hline FL3d & $-0.65 * * *$ & $0.43 * *$ & $0.8^{* * *}$ & 0.23 & -0.01 & 0.12 & -0.04 & 0.14 & 0.06 \\
\hline FL5d & $-0.69 * * *$ & $0.68 * * *$ & 0.26 & 0.12 & 0.08 & 0.24 & 0.04 & 0.25 & 0.24 \\
\hline Springiness & -0.02 & 0.22 & 0.07 & 0.14 & $0.48 * * *$ & 0.23 & -0.24 & 0.42 & -0.11 \\
\hline Hardness & 0.31 & -0.22 & -0.23 & 0.24 & -0.08 & $0.84 * * *$ & 0.27 & $0.90 * * *$ & $0.52 * * *$ \\
\hline Gumminess & 0.22 & -0.13 & -0.19 & 0.35 & $0.95 * * *$ & -0.1 & $0.58 * * *$ & $0.97 * * *$ & $0.84 * * *$ \\
\hline Resilience & -0.34 & 0.05 & 0.35 & -0.32 & $-0.55 * * *$ & $-0.67 * * *$ & 0.22 & $0.49 * * *$ & $0.71 * * *$ \\
\hline Chewiness & 0.22 & -0.1 & -0.18 & $0.43 * *$ & $0.94 * * *$ & $0.99 * * *$ & $-0.66 * * *$ & -0.11 & $0.77 * * *$ \\
\hline Cohesiviness & 0.19 & 0 & -0.2 & $0.54 * * *$ & $0.67 * * *$ & $0.81 * * *$ & $-0.84 * * *$ & $0.74 * * *$ & -0.07 \\
\hline
\end{tabular}


Table 4S. QTLs identified in the Bt $\times$ Ak and Bt $\times \mathrm{Nr}$ crosses obtained with genotype datasets integrating all markers (1:1 and 1:2:1). Consistent QTLs are marked with an asterisk

\begin{tabular}{|c|c|c|c|c|c|c|c|}
\hline Trait & Cross & QTL & Year & LOD & Nearest marker & $\begin{array}{c}\text { Position } \\
\text { (cM) }\end{array}$ & $\mathbf{R}^{2}$ \\
\hline \multirow{6}{*}{ Maturity date } & \multirow{6}{*}{$\mathrm{Bt} \times \mathrm{Ak}$} & \multirow{2}{*}{ qP-MD4* } & 2013 & 9.93 & SNP_IGA_402256 & 42.9 & 47.0 \\
\hline & & & 2014 & 9.46 & SNP_IGA_401829 & 39.8 & 44.1 \\
\hline & & \multirow{2}{*}{ qP-MD5* } & 2013 & 6.22 & SNP_IGA_585500 & 30.8 & 32.8 \\
\hline & & & 2014 & 6.62 & SNP_IGA_552927 & 11.8 & 33.4 \\
\hline & & \multirow{2}{*}{ qP-MD6* } & 2013 & 4.21 & SNP_IGA_604703 & 12.6 & 23.6 \\
\hline & & & 2014 & 5.68 & SNP_IGA_605027 & 15.5 & 29.5 \\
\hline \multirow{3}{*}{$\begin{array}{l}\% \text { firmness loss } \\
\text { (day } 3)\end{array}$} & \multirow{3}{*}{$\mathrm{Bt} \times \mathrm{Ak}$} & \multirow{2}{*}{ qP-FL3d4* } & 2013 & 3.02 & SNP_IGA_394859 & 22.8 & 17.6 \\
\hline & & & 2014 & 9.56 & SNP_IGA_409371 & 61.1 & 44.4 \\
\hline & & qP-FL3d5 & 2014 & 5.64 & SNP_IGA_584315 & 27.7 & 29.3 \\
\hline \multirow{3}{*}{$\begin{array}{l}\% \text { firmness loss } \\
(\text { day } 5)\end{array}$} & \multirow{3}{*}{$\mathrm{Bt} \times \mathrm{Ak}$} & \multirow{2}{*}{ qP-FL5d4* } & 2013 & 3.25 & SNP_IGA_397228 & 27.5 & 18.8 \\
\hline & & & 2014 & 7.25 & SNP_IGA_409901 & 62.4 & 35.9 \\
\hline & & qP-FL5d5 & 2014 & 4.66 & SNP_IGA_584113 & 24.4 & 24.9 \\
\hline \multirow{2}{*}{ Springiness } & \multirow{2}{*}{$\mathrm{Bt} \times \mathrm{Ak}$} & $\mathrm{qP}-\mathrm{Spr} 4$ & 2014 & 3.8 & M12a & 53.5 & 20.8 \\
\hline & & qP-Spr5 & 2013 & 3.29 & SNP_IGA_587708 & 35.5 & 19.0 \\
\hline \multirow{5}{*}{ Hardness } & \multirow{5}{*}{$\mathrm{Bt} \times \mathrm{Ak}$} & \multirow{2}{*}{$\mathrm{qP}-\mathrm{Har} 4 *$} & 2013 & 5.73 & SNP_IGA_409901 & 62.4 & 30.7 \\
\hline & & & 2014 & 9.96 & SNP_IGA_407919 & 52.2 & 45.7 \\
\hline & & \multirow{2}{*}{ qP-Har5* } & 2013 & 5.46 & SNP_IGA_552927 & 12.2 & 29.5 \\
\hline & & & 2014 & 2.22 & SNP_IGA_595212 & 53.4 & 12.7 \\
\hline & & qP-Har6 & 2013 & 3.33 & SNP_IGA_605027 & 15.5 & 19.2 \\
\hline \multirow{4}{*}{ Gumminess } & \multirow{4}{*}{$\mathrm{Bt} \times \mathrm{Ak}$} & qP-Gum1 & 2014 & 3.18 & SNP_IGA_24703 & $60.0(\mathrm{G} 1.1)$ & 17.8 \\
\hline & & \multirow{2}{*}{ qP-Gum4* } & 2013 & 2.18 & SNP_IGA_409901 & 62.4 & 13.0 \\
\hline & & & 2014 & 6.31 & SNP_IGA_409544 & 61.4 & 32.1 \\
\hline & & qP-Gum5 & 2013 & 3.9 & SNP_IGA_552927 & 12.2 & 22.1 \\
\hline \multirow{2}{*}{ Resilience } & \multirow{2}{*}{$\mathrm{Bt} \times \mathrm{Ak}$} & qP-Res3 & 2014 & 3.32 & SNP_IGA_365048 & 83.5 & 18.4 \\
\hline & & qP-Res4 & 2013 & 5.63 & SNP_IGA_408505 & 54.9 & 30.3 \\
\hline \multirow{2}{*}{ Chewiness } & \multirow{2}{*}{$\mathrm{Bt} \times \mathrm{Ak}$} & qP-Che 5* & 2013 & 3.85 & SNP_IGA_552927 & 12.2 & 21.8 \\
\hline & & qP-Che6 & 2013 & 3.01 & SNP_IGA_617922 & 2.3 & 17.5 \\
\hline Cohecivinesc & Rty $A \mathrm{k}$ & qP-Coh1 & 2013 & 3.28 & SNP_IGA_24703 & 63.0 & 18.9 \\
\hline conesiviness & DIXAK & $\mathrm{qP}-\mathrm{Coh} 4$ & 2013 & 4.79 & SNP_IGA_408884 & 55.7 & 26.4 \\
\hline Maturity date & $\mathrm{R}+\times \mathrm{Nr}$ & D MD $4 *$ & 2013 & 9.01 & SNP_IGA_410398 & 25.4 & 60.2 \\
\hline vraturity date & $\mathrm{BlXINr}$ & $q P-I M D 44^{*}$ & 2014 & 9.97 & SNP_IGA_403152 & 20.0 & 63.1 \\
\hline & & qP-FL3d4 & 2013 & 4.98 & SNP_IGA_409274 & 26.5 & 39.9 \\
\hline (day 3) & $\mathrm{Bt} \times \mathrm{Nr}$ & aP_EI $3 \mathrm{~d} 5 *$ & 2013 & 4.03 & SNP_IGA_571548 & 19.3 & 33.8 \\
\hline & & qP-FLSAJ & 2014 & 3.91 & SNP_IGA_557489 & 5.3 & 32.4 \\
\hline & & qP-FL5d1 & 2014 & 3.44 & SNP_IGA_109648 & 25.5 & 29.2 \\
\hline & & qP-FL5d4 & 2013 & 4.34 & CPP15636 & 27.6 & 35.9 \\
\hline $\begin{array}{l}\text { \% firmness loss } \\
\text { (dav 5) }\end{array}$ & $\mathrm{Bt} \times \mathrm{Nr}$ & aP_EL $5 d 5 *$ & 2013 & 3.71 & SNP_IGA_595648 & 51.1 & 31.6 \\
\hline & & & 2014 & 5.17 & SNP_IGA_571548 & 11.6 & 40.4 \\
\hline & & qP-FL5d6 & 2013 & 3.34 & SNP_IGA_695629 & 79.5 & 29.0 \\
\hline Cohesiviness & $\mathrm{Bt} \times \mathrm{Nr}$ & qP-Res4 & 2013 & 5.15 & CPP15636 & 28.6 & 41.0 \\
\hline Cohesiviness & $\mathrm{Bt} \times \mathrm{Nr}$ & $\mathrm{qP}-\mathrm{Coh} 4$ & 2014 & 3.91 & SNP_IGA_402793 & 14.7 & 33.6 \\
\hline
\end{tabular}

Table 5S. Physical positions in bp (peach sequence v2.a1) of the markers in the boundaries of the consistent QTLs with the \pm 1 LOD criterion in the 'Big Top', 'Armking' and 'Nectaross' maps.

\begin{tabular}{|l|lclr|}
\multicolumn{1}{c}{ QTL } & Year & Flanking markers & \multicolumn{1}{c}{ Boundaries } \\
\hline \multirow{3}{*}{ 'Big Top' } & \multirow{2}{*}{2013} & SNP_IGA_543179 & 246971 \\
& \multirow{2}{*}{ qP-MD5 } & & SNP_IGA_592011 & 11278685 \\
\cline { 3 - 5 } & & \multirow{2}{*}{2014} & SNP_IGA_543179 & 246971 \\
& & & SNP_IGA_559057 & 3731800 \\
\cline { 3 - 5 } & & & &
\end{tabular}




\begin{tabular}{|rrrr|}
\multirow{2}{*}{ qP-FL3d5 } & \multirow{2}{*}{2013} & SNP_IGA_543179 & 246971 \\
\cline { 2 - 4 } & \multirow{2}{*}{2014} & SNP_IGA_591896 & 11258683 \\
\hline & SNP_IGA_543786 & 467068 \\
& & SNP_IGA_585500 & 9252718 \\
\hline & & SNP_IGA_556288 & 3251268
\end{tabular}

Genome position

qP-FL5d5 2014

\begin{tabular}{|c|c|c|c|c|}
\hline & & & SNP_IGA_589371 & 10557562 \\
\hline \multirow[t]{22}{*}{ 'Armking' } & \multirow{4}{*}{ qP-MD4 } & \multirow{2}{*}{2013} & SNP_IGA_403152 & 8977975 \\
\hline & & & SNP_IGA_409351 & 10387393 \\
\hline & & \multirow{2}{*}{2014} & SNP_IGA_404165 & 9250943 \\
\hline & & & SNP_IGA_409351 & 10387393 \\
\hline & \multirow{2}{*}{ qP-FL3d4 } & \multirow{2}{*}{2013} & SNP_IGA_390941 & 6124843 \\
\hline & & & SNP_IGA_409351 & 10387393 \\
\hline & \multirow{4}{*}{ qP-FL5d4 } & \multirow{2}{*}{2013} & SNP_IGA_368627 & 117381 \\
\hline & & & SNP_IGA_409351 & 10387393 \\
\hline & & \multirow{2}{*}{2014} & SNP_IGA_401886 & 8233517 \\
\hline & & & SNP_IGA_409351 & 10387393 \\
\hline & \multirow{4}{*}{ qP-Har4 } & \multirow{2}{*}{2013} & SNP_IGA_397323 & 6582903 \\
\hline & & & SNP_IGA_409351 & 10387393 \\
\hline & & \multirow{2}{*}{2014} & SNP_IGA_401886 & 8233517 \\
\hline & & & SNP_IGA_409351 & 10387393 \\
\hline & \multirow{2}{*}{ qP-Gum4 } & \multirow{2}{*}{2014} & SNP_IGA_397323 & 6582903 \\
\hline & & & SNP_IGA_409351 & 10387393 \\
\hline & \multirow{2}{*}{ qP-Che 4} & \multirow{2}{*}{2014} & SNP_IGA_401886 & 8233517 \\
\hline & & & SNP_IGA_409351 & 10387393 \\
\hline & \multirow{4}{*}{ qP-MD6 } & \multirow{2}{*}{2013} & snp_6_5294415 & 5308481 \\
\hline & & & SNP_IGA_618376 & 893708 \\
\hline & & \multirow{2}{*}{2014} & snp_6_5294415 & 5308481 \\
\hline & & & SNP_IGA_609485 & 3540424 \\
\hline \multirow[t]{8}{*}{ 'Nectaross' } & \multirow{4}{*}{ qP-MD4 } & \multirow{2}{*}{2013} & SNP_IGA_407115 & 9947470 \\
\hline & & & SNP_IGA_440110 & 16076720 \\
\hline & & \multirow{2}{*}{2014} & SNP_IGA_408981 & 10280095 \\
\hline & & & SNP_IGA_437516 & 15182577 \\
\hline & \multirow{2}{*}{ qP-FL3d } & \multirow{2}{*}{2013} & SNP_IGA_403152 & 8977975 \\
\hline & & & SNP_IGA_449118 & 17994567 \\
\hline & \multirow{2}{*}{ qP-FL5d } & \multirow{2}{*}{2013} & SNP_IGA_401886 & 8233517 \\
\hline & & & SNP_IGA_449118 & 17994567 \\
\hline
\end{tabular}

Table 6S. Gene sequences of peach chromosomes 5 and 6 producing a significant alignment with the NAC transcription factor gene Prupe.4G186800, candidate for the maturity date (MD) trait in chromosome 4, and their position on the peach genome sequence v2.0. The gene falling within the boundaries of the QTLs that we have estimated for QTLs qP-MD5 is presented with a green background 


\begin{tabular}{|lcc|c|}
\hline Gene & E-value & chromosome & Position (bp) \\
\hline Prupe.5G006200 & $9,00 \mathrm{E}-044$ & 5 & 707.797 \\
Prupe.5G040400 & $2,00 \mathrm{E}-045$ & 5 & 4.430 .568 \\
Prupe.5G076100 & $3,00 \mathrm{E}-042$ & 5 & 9011205 \\
Prupe.5G131900 & $4,00 \mathrm{E}-043$ & 5 & 12690115 \\
Prupe.5G135400 & $1,00 \mathrm{E}-039$ & 5 & 12859766 \\
Prupe.5G146100 & $3,00 \mathrm{E}-039$ & 5 & 13431803 \\
Prupe.5G196000 & $5,00 \mathrm{E}-047$ & 5 & 15882585 \\
Prupe.5G221600 & $1,00 \mathrm{E}-049$ & 5 & 17242546 \\
Prupe.5G241300 & $4,00 \mathrm{E}-044$ & 5 & 18167430 \\
\hline Prupe.6G098600 & $3,00 \mathrm{E}-055$ & 6 & 6857507 \\
Prupe.6G134400 & $1,00 \mathrm{E}-032$ & 6 & 10621079 \\
Prupe.6G138100 & $1,00 \mathrm{E}-036$ & 6 & 11223633 \\
Prupe.6G238600 & $3,00 \mathrm{E}-054$ & 6 & 23830614 \\
\hline
\end{tabular}


Table 7S. Phenotypes for maturity date (MD), firmness loss (FL3d and FL5d) and acidity (D/d) of peach fruit for the parents and progeny (nb 1-85) of 'Big Top' $\mathrm{x}$ 'Armking' and genotypes for closest markers to qP-MD5 in 'Big Top' (M1=SNP_IGA_589219), qP-MD4 in 'Armking' (M2=SNP_IGA_409351) and qP-MD6 in 'Armking' (M3=SNP_IGA_605368). Plants with the most favorable HAA genotype (\#18, 68, 70 and 78) have phenotypes comparable to'Big Top' for the MD and FL traits.

2013

2014

Plant nb. MD pFLd3 pFLd5 MD pFLd3 pFLd5 M1 M2 ${ }^{\text {a }}$ M3 $D / d^{\text {b }}$

\begin{tabular}{|c|c|c|c|c|c|c|c|c|c|c|}
\hline 'Big Top' & 189 & 15.6 & 7.1 & 174 & 2.2 & 35.1 & $\mathrm{H}$ & $\mathrm{H}$ & - & SA \\
\hline 'Armking' & 178 & 62.5 & 87.6 & 163 & 75.3 & 71.8 & - & $\mathrm{H}$ & $\mathrm{H}$ & $\mathrm{AC}$ \\
\hline 18 & 185 & 8.7 & 30.6 & 167 & 22.7 & 15.7 & $\mathrm{H}$ & A & A & SA \\
\hline 68 & 189 & 25.3 & 60.2 & 170 & 5.9 & 14.4 & $\mathrm{H}$ & A & A & SA \\
\hline 70 & 192 & 24.6 & 27.0 & 170 & 30.5 & 59.6 & $\mathrm{H}$ & A & A & $\mathrm{AC}$ \\
\hline 78 & 185 & 19.0 & 40.9 & 170 & 6.4 & 15.4 & $\mathrm{H}$ & A & A & SA \\
\hline 7 & 196 & 29.7 & 64.8 & 181 & 9.3 & 57.1 & $\mathrm{H}$ & A & $\mathrm{H}$ & SA \\
\hline 8 & 189 & 41.9 & 50.6 & 174 & 27.5 & 72.0 & $\mathrm{H}$ & A & $\mathrm{H}$ & $\mathrm{AC}$ \\
\hline 13 & 199 & 67.7 & 70.1 & 181 & 2.9 & 22.2 & $\mathrm{H}$ & A & $\mathrm{H}$ & SA \\
\hline 25 & 199 & 61.3 & 72.2 & 181 & 8.9 & 40.7 & $\mathrm{H}$ & A & $\mathrm{H}$ & SA \\
\hline 26 & 192 & -3.3 & 57.9 & 174 & 21.0 & 58.6 & $\mathrm{H}$ & A & $\mathrm{H}$ & SA \\
\hline 27 & 199 & 69.8 & 79.4 & 184 & -34.6 & 29.1 & $\mathrm{H}$ & A & $\mathrm{H}$ & SA \\
\hline 30 & 185 & 32.8 & 19.9 & 177 & 29.4 & 53.1 & $\mathrm{H}$ & A & $\mathrm{H}$ & $\mathrm{AC}$ \\
\hline 35 & 189 & 20.6 & 17.4 & 174 & 14.6 & 66.1 & $\mathrm{H}$ & A & $\mathrm{H}$ & $\mathrm{AC}$ \\
\hline 39 & 192 & 28.1 & 61.0 & 174 & 24.9 & 25.1 & $\mathrm{H}$ & A & $\mathrm{H}$ & $\mathrm{AC}$ \\
\hline 44 & 199 & 57.4 & 72.1 & 184 & -27.2 & -2.3 & $\mathrm{H}$ & A & $\mathrm{H}$ & SA \\
\hline 45 & 199 & 51.5 & 68.6 & 181 & 12.4 & 48.4 & $\mathrm{H}$ & A & $\mathrm{H}$ & SA \\
\hline 46 & 176 & 0.5 & 23.7 & 167 & 38.0 & 47.4 & $\mathrm{H}$ & A & $\mathrm{H}$ & SA \\
\hline 48 & 199 & 75.7 & 80.5 & 181 & 6.0 & 63.2 & $\mathrm{H}$ & A & $\mathrm{H}$ & SA \\
\hline 52 & 199 & 65.6 & 72.1 & 177 & 21.9 & 45.6 & $\mathrm{H}$ & A & $\mathrm{H}$ & $\mathrm{AC}$ \\
\hline 58 & 199 & 77.9 & 70.1 & 181 & 4.5 & 48.3 & $\mathrm{H}$ & A & $\mathrm{H}$ & SA \\
\hline 59 & 192 & 66.1 & 70.8 & 174 & 43.4 & 64.8 & $\mathrm{H}$ & A & $\mathrm{H}$ & $\mathrm{AC}$ \\
\hline 63 & 192 & -3.6 & 45.1 & 174 & 11.9 & 42.4 & $\mathrm{H}$ & A & $\mathrm{H}$ & SA \\
\hline 66 & 192 & 11.1 & 27.8 & 174 & 33.7 & 41.3 & $\mathrm{H}$ & A & $\mathrm{H}$ & $\mathrm{AC}$ \\
\hline 76 & 203 & 64.1 & 64.8 & 181 & 15.4 & 61.0 & $\mathrm{H}$ & A & $\mathrm{H}$ & SA \\
\hline 83 & 189 & 25.4 & 50.4 & 181 & 35.6 & 82.6 & $\mathrm{H}$ & A & $\mathrm{H}$ & SA \\
\hline 1 & 185 & 47.0 & 79.2 & 170 & 41.8 & 67.7 & A & A & A & $\mathrm{AC}$ \\
\hline 4 & 192 & 47.0 & 54.3 & 174 & 22.9 & 50.0 & A & A & A & SA \\
\hline 5 & 178 & -11.1 & 47.7 & 163 & 14.6 & 21.3 & A & A & A & $\mathrm{AC}$ \\
\hline 9 & 185 & 31.0 & 77.7 & 167 & 2.7 & 33.8 & A & A & A & $\mathrm{AC}$ \\
\hline 17 & 176 & 26.1 & 7.8 & 163 & 19.5 & 65.7 & A & A & A & $\mathrm{AC}$ \\
\hline 29 & 178 & 23.5 & 66.5 & 167 & 37.4 & 57.6 & A & A & A & $\mathrm{AC}$ \\
\hline 32 & 172 & 46.1 & 48.1 & 161 & 54.0 & 65.2 & A & A & A & $\mathrm{AC}$ \\
\hline 53 & 192 & 54.8 & 63.0 & 174 & 22.1 & 69.7 & A & A & A & $\mathrm{AC}$ \\
\hline 57 & 192 & 9.3 & 48.4 & 174 & 34.4 & 44.3 & A & A & A & $\mathrm{AC}$ \\
\hline 64 & 192 & 25.5 & 47.5 & 170 & 20.2 & 55.5 & A & A & A & $\mathrm{AC}$ \\
\hline
\end{tabular}

a SNP_IGA_409351 segregates 1:2:1 in BtxAk. Missing data have been imputed in M2 based on the close marker SNP_IGA_404570 that segregates 1:1

${ }^{\mathrm{b}}$ Acid (AC) vs. Subacid (SA) fruit taste 
Table 7S. (Continued)

2013

2014

\begin{tabular}{|c|c|c|c|c|c|c|c|c|c|c|}
\hline nr & MD & pFLd3 & pFLd5 & MD & pFLd3 & pFLd5 & M1 & $\mathrm{M} 2^{\mathrm{a}}$ & M3 & $D / d^{\mathrm{b}}$ \\
\hline 11 & 196 & 51,1 & 76,6 & 174 & 14,0 & 60,4 & $\mathrm{~A}$ & $\mathrm{~A}$ & $\mathrm{H}$ & $\mathrm{SA}$ \\
\hline 21 & 189 & 43,6 & 35,9 & 174 & 35,2 & 63,9 & A & A & $\mathrm{H}$ & $\mathrm{AC}$ \\
\hline 24 & 189 & 18,0 & 47,1 & 181 & 40,6 & 82,7 & A & A & $\mathrm{H}$ & SA \\
\hline 43 & 192 & 42,0 & 65,6 & 174 & 38,7 & 62,7 & A & A & $\mathrm{H}$ & $\mathrm{AC}$ \\
\hline 54 & 192 & 57,8 & 70,7 & 174 & 62,9 & 76,4 & A & A & $\mathrm{H}$ & $\mathrm{AC}$ \\
\hline 55 & 189 & 43,1 & 43,7 & 170 & 57,9 & 68,2 & A & A & $\mathrm{H}$ & $\mathrm{AC}$ \\
\hline 56 & 192 & 51,8 & 69,6 & 174 & 20,8 & 51,8 & A & A & $\mathrm{H}$ & $\mathrm{AC}$ \\
\hline 61 & 192 & 44,5 & 62,0 & 181 & 58,6 & 81,3 & A & A & $\mathrm{H}$ & SA \\
\hline 72 & 192 & 34,8 & 50,2 & 174 & 18,7 & 12,3 & A & A & $\mathrm{H}$ & $\mathrm{AC}$ \\
\hline 67 & - & - & - & 181 & 0,6 & 44,0 & - & A & $\mathrm{H}$ & SA \\
\hline 3 & 172 & 4,2 & 0,6 & 161 & 31,2 & 72,7 & $\mathrm{H}$ & $\mathrm{H}$ & A & SA \\
\hline 34 & 169 & 36,6 & 73,0 & 161 & 73,5 & 77,0 & $\mathrm{H}$ & $\mathrm{H}$ & A & $\mathrm{AC}$ \\
\hline 51 & 172 & 49,4 & 71,2 & 161 & 37,2 & 61,8 & $\mathrm{H}$ & $\mathrm{H}$ & A & $\mathrm{AC}$ \\
\hline 50 & 206 & 63,3 & 60,2 & 163 & 50,4 & 68,1 & $\mathrm{H}$ & $\mathrm{H}$ & $\mathrm{H}$ & $\mathrm{AC}$ \\
\hline 85 & 182 & 76,6 & 85,1 & 170 & 65,0 & 76,3 & $\mathrm{H}$ & $\mathrm{H}$ & $\mathrm{H}$ & SA \\
\hline 6 & 169 & 40,0 & 75,7 & 161 & 54,4 & 62,0 & A & $\mathrm{H}$ & A & $\mathrm{AC}$ \\
\hline 12 & 169 & 76,5 & 87,0 & 161 & 70,2 & 70,6 & A & $\mathrm{H}$ & A & $\mathrm{AC}$ \\
\hline 16 & 178 & 2,7 & 30,4 & 167 & $-7,6$ & 31,7 & A & $\mathrm{H}$ & A & $\mathrm{AC}$ \\
\hline 19 & 178 & 25,7 & 55,7 & 167 & $-0,2$ & 46,8 & A & $\mathrm{H}$ & A & $\mathrm{AC}$ \\
\hline 33 & 172 & 31,7 & 46,8 & 161 & 39,6 & 67,8 & A & $\mathrm{H}$ & A & SA \\
\hline 36 & 172 & 68,3 & 79,2 & 163 & 62,9 & 74,2 & A & $\mathrm{H}$ & A & $\mathrm{AC}$ \\
\hline 40 & 169 & 67,5 & 78,8 & 161 & 83,2 & 79,7 & A & $\mathrm{H}$ & A & $\mathrm{AC}$ \\
\hline 47 & 169 & 63,8 & 75,2 & 163 & 71,6 & 69,9 & A & $\mathrm{H}$ & A & $\mathrm{AC}$ \\
\hline 49 & 172 & 54,8 & 65,1 & 163 & 71,1 & 80,1 & A & $\mathrm{H}$ & A & - \\
\hline 69 & 169 & 78,5 & 84,8 & 161 & 81,3 & 88,1 & A & $\mathrm{H}$ & A & $\mathrm{AC}$ \\
\hline 73 & 169 & 63,4 & 83,7 & 161 & 69,4 & 80,6 & A & $\mathrm{H}$ & A & $\mathrm{AC}$ \\
\hline 79 & 169 & 78,9 & 82,5 & 161 & 68,1 & 80,5 & A & $\mathrm{H}$ & A & $\mathrm{AC}$ \\
\hline 80 & 172 & 61,2 & 80,8 & 161 & 79,9 & 90,0 & A & $\mathrm{H}$ & A & $\mathrm{AC}$ \\
\hline 81 & 172 & 62,9 & 70,6 & 161 & 47,4 & 81,1 & A & $\mathrm{H}$ & A & SA \\
\hline 15 & 178 & 63,3 & 76,1 & 167 & 8,5 & 62,5 & $\mathrm{~A}$ & $\mathrm{H}$ & $\overline{\mathrm{H}}$ & SA \\
\hline 22 & 172 & 63,5 & 61,4 & 161 & 48,3 & 69,1 & A & $\mathrm{H}$ & $\mathrm{H}$ & $\mathrm{AC}$ \\
\hline 23 & 178 & 56,6 & 72,0 & 163 & 53,5 & 70,2 & A & $\mathrm{H}$ & $\mathrm{H}$ & SA \\
\hline 37 & 172 & 39,2 & 60,0 & 163 & 57,9 & 74,6 & A & $\mathrm{H}$ & $\mathrm{H}$ & $\mathrm{AC}$ \\
\hline 38 & 172 & 59,8 & 76,7 & 163 & 66,4 & 75,0 & A & $\mathrm{H}$ & $\mathrm{H}$ & SA \\
\hline 60 & 176 & 62,8 & 59,3 & 163 & 69,6 & 67,4 & A & $\mathrm{H}$ & $\mathrm{H}$ & $\mathrm{AC}$ \\
\hline 62 & 176 & 62,8 & 37,9 & 163 & 68,1 & 72,2 & A & $\mathrm{H}$ & $\mathrm{H}$ & SA \\
\hline 75 & 176 & 69,7 & 75,4 & 163 & 69,4 & 69,1 & A & $\mathrm{H}$ & $\mathrm{H}$ & $\mathrm{AC}$ \\
\hline 77 & 176 & 62,3 & 64,4 & 163 & 74,7 & 68,6 & A & $\mathrm{H}$ & $\mathrm{H}$ & $\mathrm{AC}$ \\
\hline 82 & 176 & $-9,3$ & 19,9 & 163 & 29,8 & 55,9 & A & $\mathrm{H}$ & $\mathrm{H}$ & SA \\
\hline 14 & - & - & - & 161 & 67,5 & 84,0 & - & $\mathrm{H}$ & A & $\mathrm{AC}$ \\
\hline 31 & - & - & - & 161 & 32,3 & 74,2 & - & $\mathrm{H}$ & A & $\mathrm{AC}$ \\
\hline
\end{tabular}

Genetic analysis of the slow melting flesh character in peach

Tree Genetics and Genomes

Octávio Serra, Jordi Giné-Bordonaba, Iban Eduardo, Joan Bonany, Gemma Echeverría, Christian Larrigaudière, and Pere Arús 
Corresponding author: Pere Arús

e-mail: pere.arus@irta.cat

Affiliation: IRTA. Centre de Recerca en Agrigenòmica CSIC-IRTA-UAB-UB, Campus UAB, Cerdanyola del Vallès (Bellaterra), 08193 Barcelona, Spain;

Supplementary Figures $1 \mathrm{~S}$ and 2S 
Figure 1S - Distribution of the traits analyzed in this work for Bt×Ak population in 2013 and 2014. Distribution curves are displayed above histograms. Green curves are for normally distributed data according to a Shapiro-Wilk normality test, red curves are not normal.
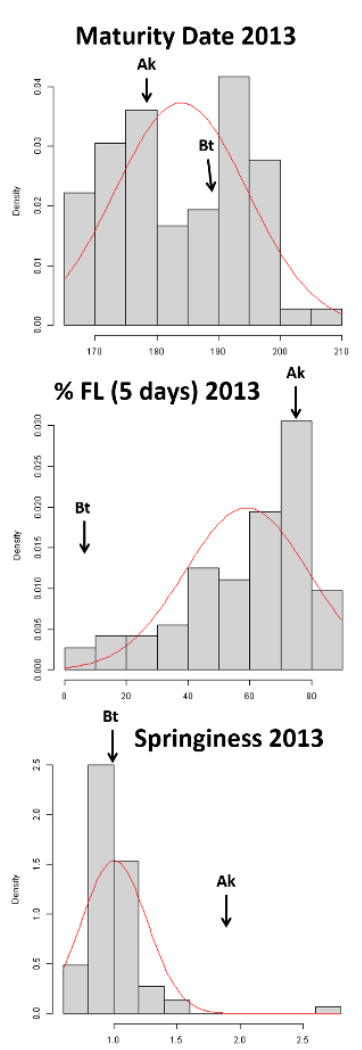

Gumminess 2013

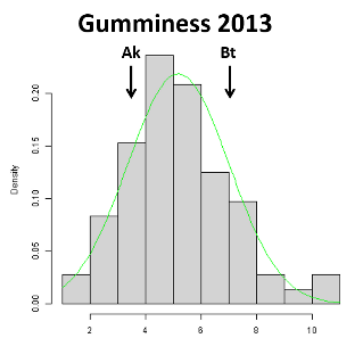

Chewiness 2013

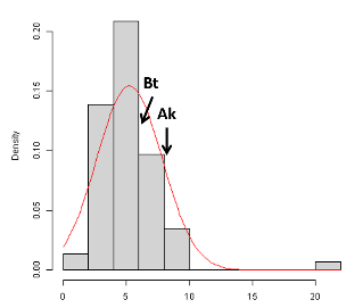

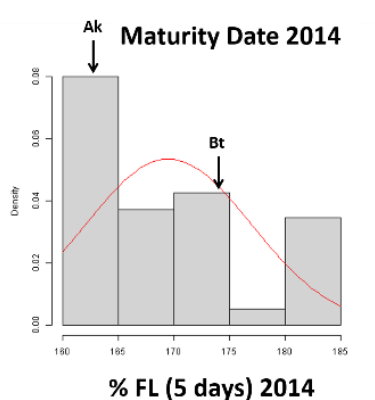
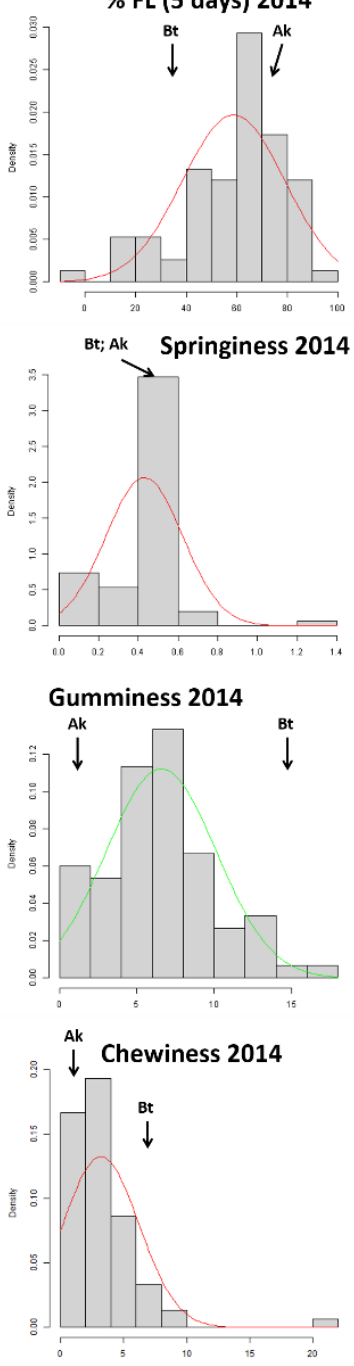
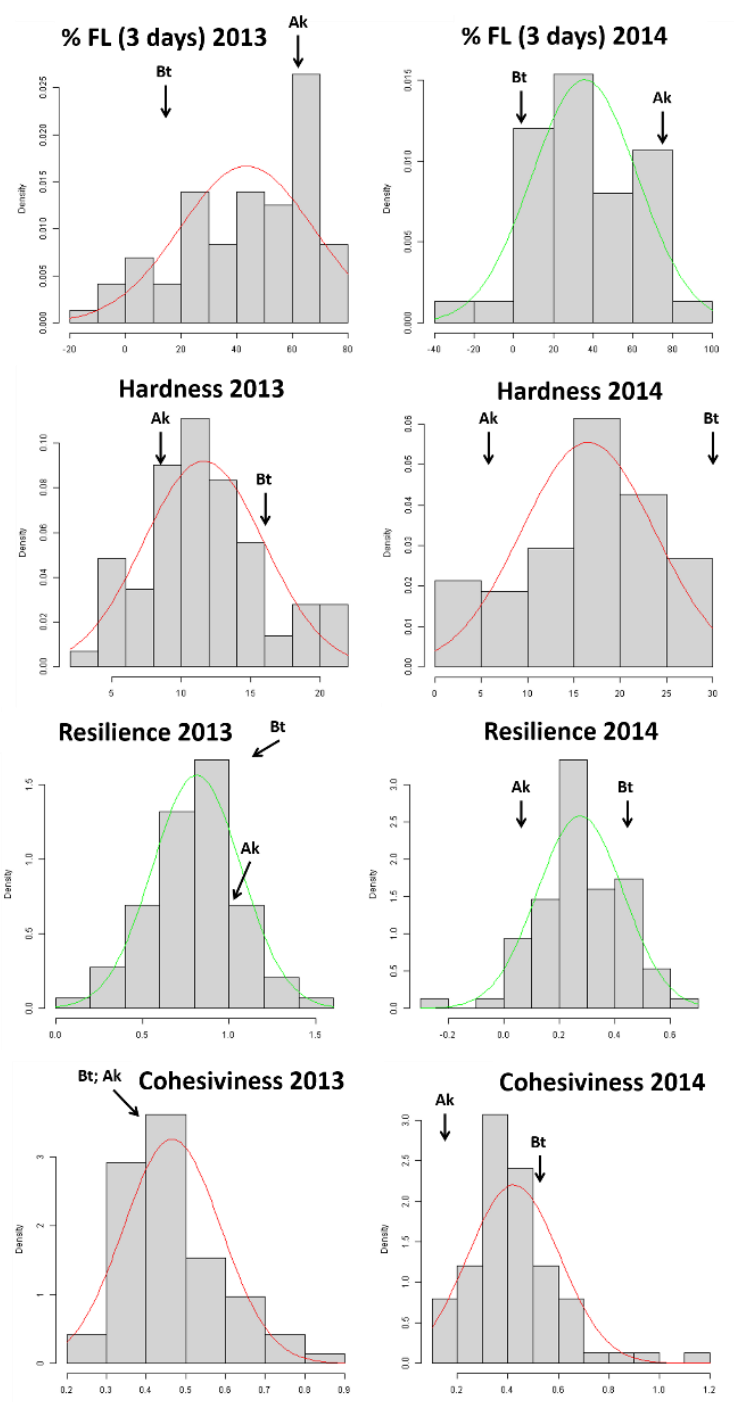
Figure 2S - Distribution of the traits analyzed in this work for Bt×Nr population in 2013 and 2014. Distribution curves are displayed above histograms. Green curves are for normally distributed data according to a Shapiro-Wilk normality test, red curves are not normal.
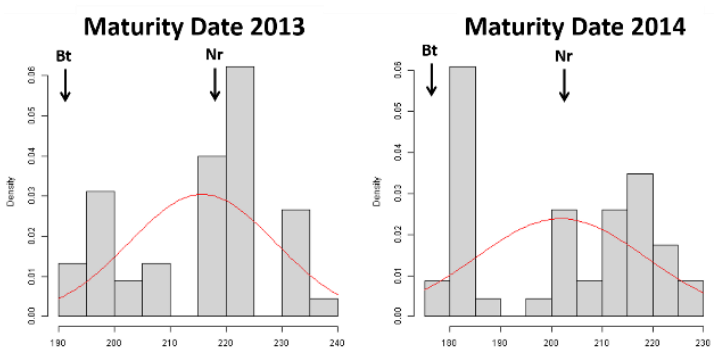

$\%$ FL (5 days) 2013
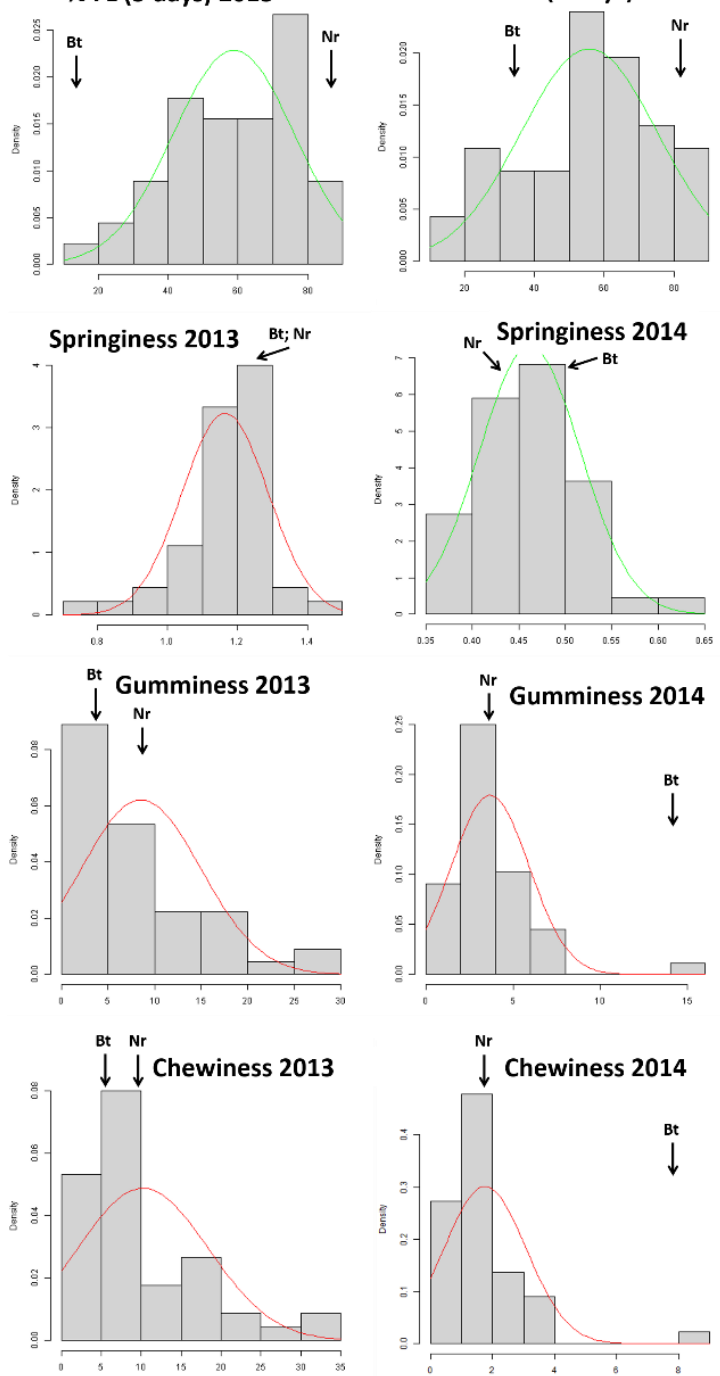
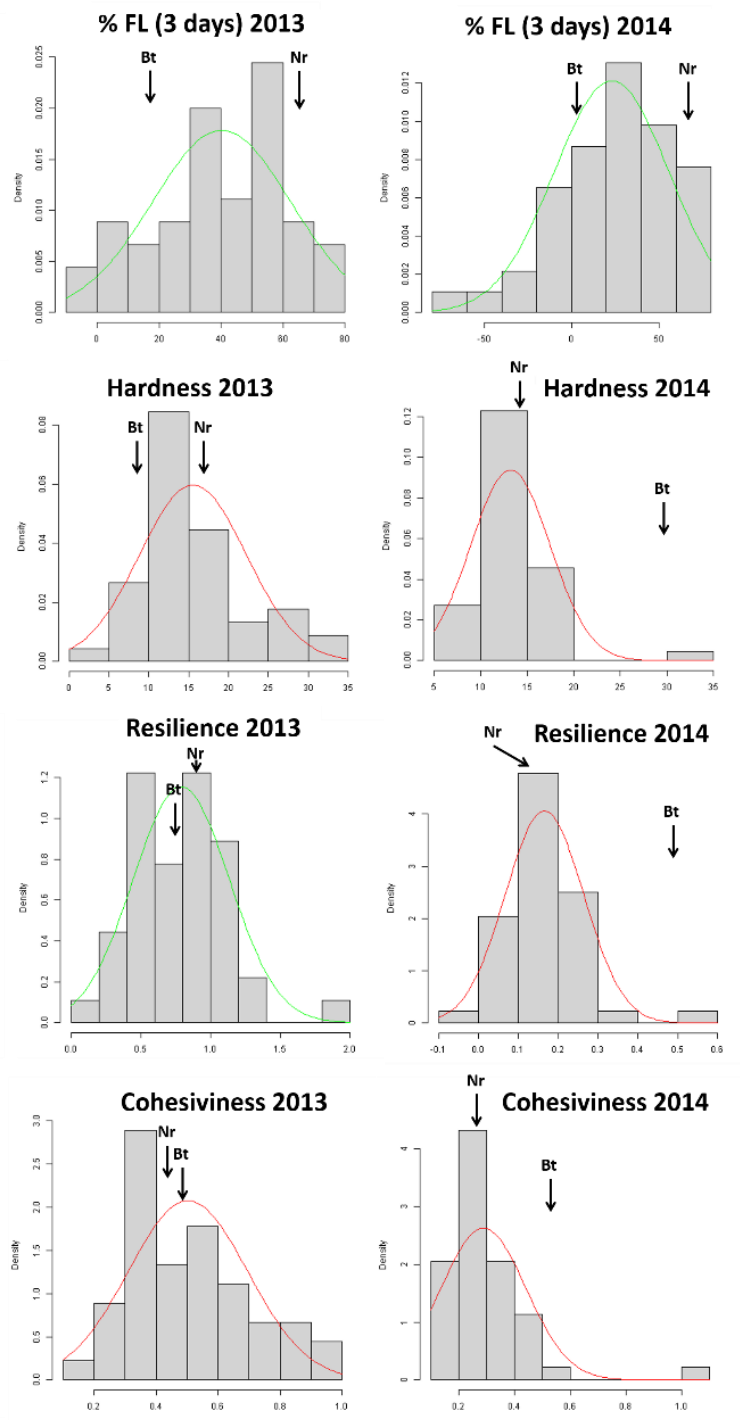